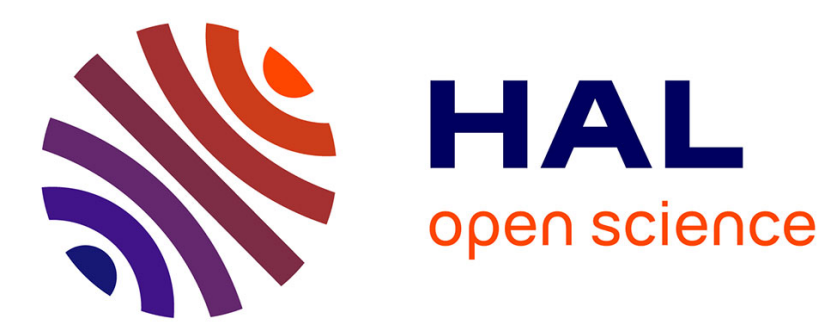

\title{
Nanoscale transport properties at silicon carbide interfaces
}

F Roccaforte, F Giannazzo, V Raineri

\section{To cite this version:}

F Roccaforte, F Giannazzo, V Raineri. Nanoscale transport properties at silicon carbide interfaces. Journal of Physics D: Applied Physics, 2010, 43 (22), pp.223001. 10.1088/0022-3727/43/22/223001. hal-00569617

\section{HAL Id: hal-00569617 https://hal.science/hal-00569617}

Submitted on 25 Feb 2011

HAL is a multi-disciplinary open access archive for the deposit and dissemination of scientific research documents, whether they are published or not. The documents may come from teaching and research institutions in France or abroad, or from public or private research centers.
L'archive ouverte pluridisciplinaire HAL, est destinée au dépôt et à la diffusion de documents scientifiques de niveau recherche, publiés ou non, émanant des établissements d'enseignement et de recherche français ou étrangers, des laboratoires publics ou privés. 


\title{
Nanoscale transport properties at silicon carbide interfaces
}

\author{
F Roccaforte, F Giannazzo and V Raineri \\ Consiglio Nazionale delle Ricerche - Istituto per la Microelettronica e Microsistemi (CNR-IMM), \\ Strada VIII n. 5, Zona Industriale, I-95121 Catania, Italy \\ E-mail: fabrizio.roccaforte@imm.cnr.it, filippo.giannazzo@imm.cnr.it, vito.raineri@imm.cnr.it
}

\begin{abstract}
Wide band gap semiconductors promise devices with performances not achievable using silicon technology. Among them, Silicon Carbide ( $\mathrm{SiC}$ ) is considered the top-notch material for a new generation of power electronic devices, ensuring the improved energy efficiency requested in the modern society. In spite of the significant progresses achieved in the last decade in the material quality, there are still several scientific open issues related to the basic transport properties at $\mathrm{SiC}$ interfaces and ion-doped regions that can affect the devices performances, keeping them still far from their theoretical limits. Hence, significant efforts in fundamental research at nanoscale have become mandatory to better understand the carrier transport phenomena, both at surfaces and interfaces. In this paper, the most recent experiences on nanoscale transport properties will be addressed, reviewing the relevant key points for the basic devices building blocks. The selected topics include the major concerns related to the electronic transport in metal/SiC interfaces, to the carrier concentration and mobility in ion-doped regions, and to channel mobility in metal/oxide/SiC systems. Some aspects related to interfaces between different $\mathrm{SiC}$ polytypes are also presented. All these issues will be discussed considering the current status and the drawbacks of $\mathrm{SiC}$ devices.
\end{abstract}

PACS: 73.30.+y, 73.40.-c, 85.30.Tv, 84.30.Jc

Keywords: Silicon Carbide, Schottky barrier, interfaces, mobility, power devices

\section{Introduction}

Nowadays, the increasing need of electric power, the rising costs of energy and its impact on environment have become important concerns in our society. Only reducing the consumption of electric energy through its efficient use also in electronics systems can lead to a remarkable decrease of the overall energy consumption. Then, the request of higher energy efficiency is investing the Information and Communication Technology (ICT), the consumer electronics, the household appliance and transportation (e.g., electric vehicles). Consequently, the power electronics semiconductor roadmap cannot be anymore approached simply by increasing the electric power density to reduce the device cost, as commonly assumed so far, but rather more efficient devices should be implemented.

Wide band gap semiconductors such as Silicon Carbide (SiC), Gallium Nitride (GaN) and related compounds are the most promising materials for the next generation of advanced electronic power devices to meet the requirements of high performance integrated electronics systems, since they can achieve performances, including energy efficiency, well beyond the silicon limits [1,2,3]. Then, for many applications, the implementation of devices in these materials can be justified in spite of the high material costs. The outstanding physical properties of wide band gap materials can lead to tremendous advantages for high-temperature, highpower and high-frequency operation, as well as low noise capability and radiation hardness. Devices with very low specific on-resistance $\left(R_{o n}\right)$ and high blocking voltages are in principle possible, driving to ideal "zero-loss" components in terms of the dissipated power. 
$\mathrm{SiC}$ is undoubtedly the wide band gap semiconductor that has reached the largest maturity in terms of crystal quality, wafer size and device processing capability. It is well known that $\mathrm{SiC}$ presents a large number of different crystalline forms called "polytypes", differing from the stacking sequences of the basic Si-C bilayer component [4]. The most common polytypes used in electronics are $3 \mathrm{C}-\mathrm{SiC}, 6 \mathrm{H}-\mathrm{SiC}$ and $4 \mathrm{H}-\mathrm{SiC}$. Table 1 reports the relevant physical properties of these crystals, compared with those of silicon ( $\mathrm{Si}$ ). For enhanced devices performances, an important feature is the wide band gap of $\mathrm{SiC}$ polytypes, which determines the high critical breakdown field $E_{B}(1-3 \mathrm{MV} / \mathrm{cm})$, typically around one order of magnitude larger than that of $\mathrm{Si}(0.3$ $\mathrm{MV} / \mathrm{cm}$ ). As a matter of fact, a higher critical field results into a higher breakdown voltage for a fixed thickness of the device active layer. Additionally, for a targeted device breakdown voltage, it is possible the use of thinner epilayers, thus allowing to significantly reduce the $R_{o n}$ and, hence, the power losses. Finally, the wide band gap leads to a very low intrinsic carrier concentration $n_{i}$ (several order of magnitudes lower than in $\mathrm{Si}$ ), which is important to guarantee low leakage currents even at high temperatures operation.

Starting from the beginning of the 1990s, SiC material growth and device technology have seen tremendous progresses, culminated in the availability of high quality hexagonal, large area single crystalline wafers $(6 \mathrm{H}-\mathrm{SiC}$ and $4 \mathrm{H}-\mathrm{SiC})$, suitable for electronics devices fabrication. In particular, the evolution of $4 \mathrm{H}-\mathrm{SiC}$ material led recently to very low $\left(<1 \mathrm{~cm}^{-2}\right)$ or even zero "micropipe" density in commercial wafers up to 100 $\mathrm{mm}$ in diameter [5], while $150 \mathrm{~mm}$ wafers are expected for 2011. The evolution of the material quality was accompanied by the demonstration of several devices suitable for high-power applications $[6,7,8,9]$, although the only market success has taken place in the area of Schottky diodes $[9,10]$. In this sense, the gradual elimination of micropipes (that are electrically "killer defects") in $\mathrm{SiC}$ epilayers represented a fundamental step towards ideal metal/SiC Schottky barriers and high device yield [11,12].

In spite of the significant progresses attained in the last decade, several scientific issues are still open. In particular, to date many crucial aspects concerning the carrier transport at surfaces and interfaces remain unclear. A nanoscale scientific approach, also involving innovative characterization, can be the way to unhinge the field and introduce a groundbreaking knowledge to finally achieve the material theoretical limits.

In this review paper, some recent advances on the charge transport at $\mathrm{SiC}$ interfaces are reported. In particular, the paper will focus on the major concerns related to the transport in metal/SiC Schottky barriers at the nanoscale, and on the critical issues related to the local carrier mobility, going from bulk and epi material, to properties in ion-implanted regions. Finally, the challenging channel mobility at $\mathrm{SiO}_{2} / \mathrm{SiC}$ interfaces and some aspects related to heteropolytype $\mathrm{SiC}$ interfaces are discussed.

All these issues will be argued in the framework of the present status of SiC technology, considering the perspectives and the common drawbacks in $\mathrm{SiC}$ electronic devices technology.

\section{Electronic transport through metal/SiC interfaces}

The electronic transport across metal/SiC interfaces, i.e. both Ohmic and rectifying (Schottky) contacts, has been the subject of extensive scientific investigations in the last decade $[10,13,14]$. The main reasons are the need to achieve a very-low contact resistance to reduce the passive contribution to device performances, and to attain an ideal and reliable behaviour in the forward and reverse characteristics of Schottky diodes. However, the peculiar inhomogeneous nature of metal/SiC interfaces requires the knowledge and the control of the interfacial properties at a nanoscale level, in order to predict the behaviour of macroscopic contacts and, ultimately, to achieve the desired devices performances. Only recently, a clear experimental correlation between nanoscale inhomogeneities and macroscopic properties has been demonstrated in $\mathrm{SiC}$ and other wide-band-gap materials [15]. In this way, the basic understanding of the electronic transport through metal/SiC interfaces has been significantly improved, thus providing a fundamental feedback to optimize the surface and interface processing and the metallization schemes, in relation to the particular device application. All these concepts will be discussed in this section, giving an overview of the studies on inhomogeneous Schottky barriers to SiC, by considering some important implications for practical devices fabrication.

\subsection{Nanoscale inhomogeneity of Schottky barriers to n-type SiC}


Metal/semiconductor contacts are fundamental parts of all semiconductor electronic and opto-electronic devices. The most important parameter in these systems is the Schottky barrier height (SBH). The control and reproducibility of the electrical properties of Schottky barriers are often critical issues. As a matter of fact, Schottky contacts to $\mathrm{SiC}$ often exhibit a non-ideal behaviour in the current-voltage characteristics (I-V), with even a large dispersion from one device to another and significant anomalies in the temperature dependence of the electrical parameters (Schottky barrier height, ideality factor,...). Therefore, it is clearly important to understand the nature of such non-ideal behaviour, investigating to which extent the material quality and/or the surface preparation play a role in the carrier transport through the interfaces.

Table 2 reports the values of the Schottky barrier height $\left(\Phi_{B}\right)$ for different metal/SiC contacts, for the most common polytypes, 3C-SiC [16,17, 18 ], 6H-SiC [19, 20,21,22, 23, 24, 25, 26,] and 4H-SiC $[27,28,29,30,31,32,33,34,35,36]$. These values are a selection among a large amount of published data. They were determined by the analysis of the forward I-V characteristics of Schottky diodes (see Ref. [37] for details on this method). The data refer to the case of non-annealed contacts on n-type material and to the Si-face terminated for the hexagonal polytypes. The small amount of data available for 3C-SiC depends on the poor material quality available, which has limited the studies on Schottky contacts in the last years. More data can be found for the hexagonal polytypes, where the most commonly used metals for Schottky contacts are $\mathrm{Ti}$ and $\mathrm{Ni}$, which typically show a higher reproducibility of the barrier height, and have been easily integrated in the fabrication of Schottky diodes. In other works, "non conventional" metallization schemes have been recently investigated, like metal borides [38], or rare earth oxides [39], which should give a better thermal stability of the barrier.

First, it must be pointed out that the experimental values of $\Phi_{B}$ reported in Table 2 are lower than the theoretical ones predicted by the classical Schottky-Mott theory, as the difference of the metal work function and the semiconductor electron affinity [40]. Hence, different physical models must be invoked to explain the reduced I-V barrier height and the deviation from the ideal behaviour observed in metal/SiC contacts. As an example, the occurrence of carrier transport mechanisms other than the thermionic emission, such as tunnelling current through the barrier [41] could be considered. However, at the typical doping levels used for n-type SiC Schottky diodes $\left(<5 \times 10^{16} \mathrm{~cm}^{-3}\right)$, the effect of tunnelling through the barrier at room temperature is very low under forward bias, and it may become significant only under strong reverse bias [42].

Hence, a common approach is to consider of a thin interfacial insulating layer, introduced to describe the presence of interface states at the metal/SiC contact [43]. These states, located at the interface between the semiconductor and the insulating layer, are characterized by a neutral level $\Phi_{0}$, i.e. the energy level (relative to the valence band) to which the interface states are filled when the surface is neutral.

According to this description, it is useful to report the dependence of the SBH on the metal work function.

The SBH values are reported in figure 1 as a function of the metal work function $\Phi_{m}$ for the three SiC polytypes. A general trend can be observed, with the values of $\Phi_{B}$ that increase with increasing metal work function $\Phi_{m}$. Moreover, the experimental values of $\Phi_{B}$ are, on average, lower in the case of $3 \mathrm{C}$-SiC, and increase for $6 \mathrm{H}-\mathrm{SiC}$ and $4 \mathrm{H}-\mathrm{SiC}$, respectively. This behaviour can be explained by the different values of electron affinity, i.e., 3.8 $\mathrm{eV}$ in $3 \mathrm{C}-\mathrm{SiC}, 3.3 \mathrm{eV}$ in $6 \mathrm{H}-\mathrm{SiC}$, and $3.1 \mathrm{eV}$ in $4 \mathrm{H}-\mathrm{SiC}$. Besides this polytype dependence, figure 1 gives useful insights on the intrinsic nature of the metal/SiC interface. The slope of the $\Phi_{B}$ vs $\Phi_{m}$ plot is the so-called "interface index" $S$, and is defined as $\frac{\partial \Phi_{B}}{\partial \Phi_{m}}$ or $\frac{\partial \Phi_{B}}{\partial \chi_{m}}$, depending on whether the work function $\Phi_{m}$ or the electronegativity $\chi_{\mathrm{m}}$ of the metal is considered. The interface index $\mathrm{S}$ is a parameter that gives an indication on the ideality of the metal/semiconductor Schottky contacts. In particular, for $S \approx 1$ a pure Schottky-Mott behaviour is expected, with the barrier height given by the difference of the metal work function and the semiconductor electron affinity $\left(\Phi_{B}=\Phi_{m}-\chi_{s}\right)$. On the other hand, for $S \approx 0$ a complete "Fermi level pinning" to the defined position $\Phi_{0}$ occurs and the carrier transport properties are almost uniquely determined by the interface states, independently of the metal [44]. Under these conditions, known as the Bardeen limit [45], the barrier height value is given by $\Phi_{B}=E_{g}-\Phi_{0}$, where $E_{g}$ is the forbidden energy gap.

For the data reported in figure 1 the values of the interface index $S$ are lower than 1, meaning that a partial Fermi level pinning at the surface occurs. It is worth noting that similar values of the interface index are found for three 
polytypes, being $\mathrm{S}$ in $3 \mathrm{C}-\mathrm{SiC}(0.32)$ only slightly lower than the values found in the hexagonal polytypes $(0.40$ 0.41). According to the model proposed by Kurtin et al. [46], the interface index is expected to increase with the degree of ionicity of the semiconductor, defined as the difference in the electronegativities of the two components $\left(\Delta \chi_{\mathrm{s}}\right)$. Hence, due to the degree of ionicity of $\operatorname{SiC}\left(\Delta \chi_{\mathrm{s}}=0.65 \mathrm{eV}\right)$ the behaviour of metal/SiC interfaces is intermediate between a strong Fermi level pinning (Bardeen limit) and an ideal Schottky behaviour (Schottky-Mott limit), in agreement with the results shown in figure 1. Edwing et al. [47] recently modelled the non-ideal behaviour of Schottky diodes on $4 \mathrm{H}-\mathrm{SiC}$ under forward bias by the presence of two non-interacting barriers put in parallel (a high barrier and a low barrier). In particular, extracting the value of $\Phi_{B}$ for the high barrier regions they found a similar dependence on the metal work function (with $S=0.45$ ) as the one deduced by the data in figure 1. On the other hand, the low barrier regions of the diodes gave no dependence on the metal work function, indicating the complete pinning of the Fermi level. This latter was ascribed to the presence of specific defects in the diodes showing strongly non-ideal behaviour. Only a few authors reported that under specific surface treatments an "un-pinned" Fermi level $(S \approx 1)$ can be achieved in metal/6H-SiC contacts, with the virtual elimination of interface states and the achievement of the ideal barrier value [48].

The interfacial layer model and the presence of surface states cannot fully explain important aspects related to the carrier transport through metal/SiC Schottky interfaces, such as the temperature dependence of the electrical parameters $n$ and $\Phi_{B}$, typically observed in Schottky diodes. In fact, the model predicts a temperature independent ideality factor $n[42,43]$.

Hence, another view to describe non-ideal metal/SiC Schottky barriers, consistent with the behavior of the SBH in macroscopic diodes, is to consider the "lateral uniformity" of the barrier at a nanoscale level. In this context, a deeper understanding was accomplished in the last years, thanks to the development of novel techniques enabling to monitor the local transport properties with a nm-scale spatial resolution [49].

Starting from the evidence that the I-V characteristics of macroscopic diodes show significant variations from device to device, although the interface is prepared under the same chemical conditions, $\operatorname{Im}$ et al. $[25,50]$ gave the first nanoscale approach to explain the non-ideal electrical behavior of Schottky contacts to SiC. In particular, they monitored the local fluctuations of the $\mathrm{SBH}$ in the $\mathrm{Pd} / 6 \mathrm{H}-\mathrm{SiC}$ system by means of Ballistic Electron Emission Microscopy (BEEM) [51], acquiring several BEEM spectra at different locations over the sample surface. The local Schottky barrier height values showed a Gaussian distribution, indicating that the metal/SiC interface is not characterized by a unique value of $\Phi_{B}$ but rather a lateral inhomogeneity of the barrier height is present. Correlating the behaviour of the macroscopic diodes with the nanoscale measurements of the local barrier height it was possible to explain the electronic transport and the non-ideality of the metal/SiC interface using the Tung's model on "inhomogeneous" Schottky barriers [52]. Accordingly, the inhomogeneous Schottky barrier can be described as a distribution of low barrier "patches" embedded inside a background of a higher uniform barrier [52]. Clearly, the presence of nanometer-size patches with a low barrier can give a disproportionately large effect on the I-V characteristics, due to the exponential dependence on the barrier height of the current flow through the metal/semiconductor contact. Assuming a geometry based on circular patches of low SBH embedded in a region of higher SBH $\Phi_{B 0}$, the ideality factor $n$ and the effective barrier height $\Phi_{\text {eff }}$ can be expressed as [53]

$$
\begin{aligned}
& n=1+\frac{\gamma}{3 \eta^{\frac{1}{3}} V_{b b}^{\frac{2}{3}}} \\
& \Phi_{e f f}=\Phi_{B 0}-\gamma\left(\frac{V_{b b}}{\eta}\right)^{\frac{1}{3}}
\end{aligned}
$$

where $V_{b b}$ is the band bending (i.e. the diffusion potential of the diode) [43] and $\eta=\varepsilon_{s} / q N_{D}$, $\varepsilon_{\mathrm{s}}$ being the permittivity of the material and $N_{D}$ the doping concentration. Here, $\gamma$ is a parameter that takes into account the size and the barrier height of the single patch [53].

The above formalism clearly indicates that a nanoscale lateral inhomogeneity of the Schottky interface manifests itself through a deviation from the ideal behavior $(n>1)$ and a lowering of the experimental SBH with respect to the theoretical one $\left(\Phi_{\text {eff }}<\Phi_{B 0}\right)$ in macroscopic diodes. 
This description allowed to explain a large number of anomalies of the electrical behaviour of Schottky contacts in SiC. As an example, Roccaforte et al. [34] investigated the electrical behaviour of $\mathrm{Ni}_{2} \mathrm{Si} / 4 \mathrm{H}-\mathrm{SiC}$ Schottky diodes at different temperatures, to understand the microscopic nature of the barrier. Figure 2 reports the values of $n$ and $\Phi_{B}$ as a function of the temperature for $\mathrm{Ni}_{2} \mathrm{Si} / 4 \mathrm{H}-\mathrm{SiC}$ Schottky diodes. As can be seen, both $n$ and $\Phi_{B}$ exhibit a significant dependence on the junction temperature. In particular, by decreasing the temperature the ideality factor increases, while the value of the SBH decreases. The temperature dependence of $n$ and $\Phi_{B}$ can be interpreted as the "macroscopic manifestation" of a nanoscale lateral inhomogeneity of the Schottky barrier. In a simplified manner, this dependence can be explained as described in the following: In a lateral inhomogeneous barrier, the current flow through the high barrier regions becomes dominant at high temperature, i.e., when the carriers can overcome the highest barrier by a nearly pure thermionic mechanism. Therefore, an ideality factor very close to one and a high value of $\Phi_{B}$ (close to the theoretical value) are measured. On the other hand, at lower temperatures, electrons have sufficient energy only to overcome the lower barrier "patches", thus leading to an increase of the ideality factor and a lowering of the $\Phi_{B}$ values. Furthermore, a linear correlation between the values of $n$ and $\Phi_{B}$ obtained at the different temperatures could be observed, as shown in the inset of figure 2. Schmitsdorf et al. [54] ascribed the correlation between $n$ and $\Phi_{B \text {, determined at }}$ room temperature on a set of different diodes, to the inhomogeneous nature of the Schottky barriers. In fact, starting from Tung's theory [52], in an inhomogeneous barrier a linear correlation between these parameters can be expected, as can be deduced by their analytical expressions given in (1) and (2) [53]. From the data reported in the inset in figure 2, an average barrier height $\Phi_{B 0}=1.69 \mathrm{eV}$ could be determined by the extrapolation of the barrier height at $n=1$, that is the barrier height of the "homogeneous" $\mathrm{Ni}_{2} \mathrm{Si} / 4 \mathrm{H}-\mathrm{SiC}$ interface [34]. Using this approach, the underestimation of the Richardson's constant in $4 \mathrm{H}-\mathrm{SiC}$, often reported in literature, was attributed to the inhomogeneity of the barrier, where the effective area $A_{\text {eff }}$ involved in the current transport can be significantly lower (even a few percents) than the geometric area of the contact [34]. After this study, a similar approach was successfully applied by other authors to explain the temperature dependence of the electrical characteristics of Schottky barriers on $\mathrm{SiC}[55,56]$.

A quite important nanoscale issue affecting the properties of the Schottky barrier is the surface processing. In fact, the electrical properties of Schottky contacts to SiC show a significant dependence on the surface preparation at nanoscale before metal deposition $[35,39,57,58,59,60,61]$, and on post deposition annealing. As an example, surface roughness, interfacial contaminants, residual thin oxide layers, etc., can affect the uniformity of the Schottky barrier and, consequently, lead to non-ideal I-V characteristics of Schottky contacts.

The "sacrificial oxidation" (i.e., the thermal oxidation of $\mathrm{SiC}$ followed by removal of the grown oxide layer) has been proposed as a method to obtain a "clean" surface in order to improve the electrical properties of Schottky barriers fabricated on it [58]. In fact, the consumption of a near-surface layer, which may be non-ideal in terms of crystal quality or may be contaminated during preparation, should guarantee a better homogeneity of the metal/SiC barrier. However, also the process used to remove the sacrificial oxide, and the oxidation itself, can be crucial for the nanoscale lateral homogeneity of the barrier and, hence, for the overall reproducibility of the electrical characteristics.

Giannazzo et al. [62] investigated the nanoscale homogeneity of the Schottky barrier in a Au/6H-SiC structure, with and without the presence of a nanometric non-uniform interfacial thermal oxide layer, i.e., a typical situation that may occur during device fabrication. A method based on conductive atomic force microscopy (C-AFM) was used for the local mapping of the barrier uniformity with a spatial resolution in the order of the AFM tip size [62] (see appendix A.1). Figure 3 shows the distribution of the local SBHs values of $\mathrm{Au} / \mathrm{SiC}$ contacts, with an interfacial non-uniform oxide layer and for a "clean" surface where this interlayer was removed by an appropriate wet etch in buffered hydrofluoric acid. As can be seen, a broad barrier height distribution, peaked at $1.48 \mathrm{eV}$ with a FWHM of $0.25 \mathrm{eV}$, is observed in the presence of a residual oxide layer. The average Schottky barrier height increases after optimal removal of the interlayer $(1.81 \mathrm{eV})$, where also a narrower distribution $(\sim 0.1 \mathrm{eV})$ is obtained, thus indicating a better nanoscale lateral homogeneity of the "clean" contact. This result demonstrates that only a nanoscale control of SiC surfaces can enable to approach the ideal behaviour.

Some metallic systems used as Schottky contacts to $\mathrm{SiC}$ have shown a better reproducibility of the electrical properties, being the barrier height almost independent of the surface preparation. As an example, 
nickel silicides, formed by a thermal reaction of $\mathrm{Ni}$ films with $\mathrm{SiC}$ above $600^{\circ} \mathrm{C}$, can result in a nearly ideal behaviour of the contact by the consumption of a $\mathrm{SiC}$ surface-layer during the silicidation process [61]. The high reproducibility of this process has recently been used for Schottky-type UV detectors fabricated in 4H-SiC [63], where the high barrier of $\mathrm{Ni}_{2} \mathrm{Si}$ and the low leakage current are crucial to obtain a high optical sensitivity. Furthermore, due to the high $\mathrm{SBH}, \mathrm{Ni}_{2} \mathrm{Si}$ exhibits a lower leakage current than $\mathrm{Ti}$ (the low-barrier metal typically used for power device applications) and, hence, can be suitable for increasing the maximum operation temperature of Schottky diodes for high-temperature and/or high voltage applications [22].

Beyond the intrinsic inhomogeneous nature of the Schottky barrier and the influence of the surface preparation, point defects in the surface-region and/or in the bulk can also affect the carrier transport through metal/SiC Schottky interfaces. Recently, new fundamental insights have been achieved by correlating the surface preparation with the electronic properties of both metal/SiC interfaces and bulk material. In particular, the role of the sacrificial oxidation has been recently clarified, demonstrating that the process not only consumes a layer of $\mathrm{SiC}$ but also reduces the concentration of the $\mathrm{Z}_{1} / \mathrm{Z}_{2}$ centers in $4 \mathrm{H}-\mathrm{SiC}$ in the remaining material [64]. In this way, the carrier lifetime can be increased, improving the characteristics of Schottky diodes. This recent finding is particularly important for $\mathrm{SiC}$ technology. In fact, the $\mathrm{Z}_{1} / \mathrm{Z}_{2}$ level is one of the most common deep centers observed in $4 \mathrm{H}-\mathrm{SiC}$ and is typically associated to an intrinsic carbon-related defect such, as a carbon vacancy $\left(V_{C}\right)$ or a carbon interstitial $\left(I_{C}\right)$ [65]. Its presence has been demonstrated to have a strong impact on the leakage current in Schottky contacts [66]. It has been argued that carbon and/or silicon atoms emitted from the $\mathrm{SiO}_{2} / \mathrm{SiC}$ interface formed during sacrificial thermal oxidation can diffuse inside the epilayer, and consequently, their interstitials annihilate via recombination with carbon vacancies, which may be the main constituent of the $Z_{1} / Z_{2}$ defect [64].

Finally, another important issue for Schottky interfaces in SiC is the possibility to tailor the Schottky barrier in power rectifiers, in order to minimize the power losses. For this purpose, a minimum on-state voltage drop is required, which in turn can be achieved by using a metal with a low SBH. This latter can however lead to an undesired increase of the leakage current under reverse bias. Hence, new devices concepts involving an engineering of the Schottky interface both at a microscopic and at a nanoscale level are required. As an example, dual-metal-pinch rectifiers formed by micrometric stripes alternating low and high barrier height metals $\left(\mathrm{Ti} / \mathrm{Ni}_{2} \mathrm{Si}\right)$ can allow to combine the advantages of the $\mathrm{Ti}\left(\Phi_{B} \approx 1.2 \mathrm{eV}\right)$ under forward bias and of the $\mathrm{Ni}_{2} \mathrm{Si}\left(\Phi_{B}\right.$ $\approx 1.6 \mathrm{eV}$ ) under reverse bias [22]. Furthermore, also new nanoscale approaches for the manufacturing of Schottky contacts to $\mathrm{SiC}$ with lower barrier have been proposed, involving the formation of $\mathrm{Au}$ nanoparticles/SiC interfaces, whose electrical properties (i.e., the barrier height) critically depend on the size of the nanoparticles $[67,68]$.

Clearly, the improved knowledge gained on the inhomogeneous nature of Schottky barriers to $\mathrm{SiC}$ is fundamental for devices applications, to identify the right surface preparation conditions, and to define the appropriate metallization schemes or post-deposition annealing in order to achieve the desired performances.

\subsection{Ohmic contacts to $\mathrm{SiC}$}

Ohmic contacts to $\mathrm{SiC}$ are typically formed by the deposition of a metal or an alloy ( $\mathrm{Ni}, \mathrm{Ti}, \mathrm{Ta}, \mathrm{Ti}-\mathrm{Al}$, $\mathrm{Ni}-\mathrm{Al}$, etc.) followed by post-annealing treatments in the temperature range of $900-1000^{\circ} \mathrm{C}$. For the n-type doped material, Ni-based contacts are used. While Schottky behaviour is observed in $\mathrm{Ni} / \mathrm{SiC}$ contacts annealed at around $600^{\circ} \mathrm{C}$, a transition to Ohmic contact gradually occurs upon annealing at higher temperatures, between $600^{\circ} \mathrm{C}$ and $950^{\circ} \mathrm{C}$. Thermal annealing above $500^{\circ} \mathrm{C}$ induces a solid state reaction, leading to the formation of different nickel silicides phases $\left(\mathrm{Ni}_{32} \mathrm{Si}_{12}, \mathrm{Ni}_{2} \mathrm{Si}, \ldots\right)$, which evolve in the most stable $\mathrm{Ni}_{2} \mathrm{Si}$ upon annealing at $950^{\circ} \mathrm{C}[69,70]$. Typical values of the specific contact resistance $\rho_{c}$ of $\mathrm{Ni}_{2} \mathrm{Si}$ contacts onto heavily doped n-type $\mathrm{SiC}$ reported in the literature range between $10^{-5}-10^{-7} \Omega \mathrm{cm}^{2}$. The mechanisms of current transport and Ohmic contact formation in the $\mathrm{Ni}_{2} \mathrm{Si} / \mathrm{SiC}$ system have been widely discussed in some review papers $[13,14]$. According to the common interpretation, a high concentration of carbon vacancies at the silicide/SiC interface is generated upon annealing, acting as donors and increasing the net carrier concentration below the metal [71]. Under these conditions, the $\mathrm{Ni}_{2} \mathrm{Si} / \mathrm{SiC}$ barrier becomes narrower, thus enhancing the electron tunneling and, hence, an Ohmic conduction mechanism. Furthermore, a decrease of the homogeneity of the silicide/SiC barrier occurring by 
increasing the annealing temperatures from $600^{\circ} \mathrm{C}$ to $950^{\circ} \mathrm{C}$ (i.e., where a significant electro-structural evolution of the silicides phases is observed) can also play a role in this electrical transition [13,72].

The formation of Ohmic contacts to p-type $\mathrm{SiC}$ is more complicated than in n-type material, due to the difficulty to obtain low Schottky barrier heights values. In fact, considering the energy gap (2.35-3.28 eV) and the electron affinity (3.1-3.8 eV) of $\mathrm{SiC}$ polytypes, the valence band lies around $6 \mathrm{eV}$ away from the vacuum level. Hence, since the metals have work function in the range 4-5.5 eV, a high energy difference arises between the conducting carriers of the metal and the p-type $\mathrm{SiC}$.

Because of the low Schottky barrier, Al- or Ti/Al-based alloyed contacts are commonly used as Ohmic contacts to p-type $\mathrm{SiC}$, leading to values of specific contact resistance in the order of $10^{-3}-10^{-5} \Omega \mathrm{cm}^{2}$ [14]. However, from the experimental results reported on $\mathrm{Ti}-\mathrm{Al}$ Ohmic contacts to p-type $\mathrm{SiC}$, it is not clear whether the spiking due to intrusions of the annealed metal into $\mathrm{SiC}$ leads to an increase of the doping by Al-indiffusion or rather the intrusions themselves act as field emitters increasing the leakage current and leading to the formation of an Ohmic contact [14].

Even if some ambiguities still remain in the explanation of the Schottky-to-Ohmic transition after contacts annealing, the formation of low-resistance Ohmic contacts on heavily doped epitaxial SiC layers cannot be considered as a major technological concern. However, for many devices applications, ion-implantation is used to achieve selective area doping of $\mathrm{SiC}$. In this case, the contact properties on ion-implanted layers will depend on the local values of the carrier concentration and mobility underneath the metal. These values, in turn, are strongly related to the implantation and post-annealing conditions, and to the presence of ion-induced material defects. Obviously, some of these aspects, that are less relevant when studying contacts and interfaces properties on epitaxial layers (i.e., with a uniform doping), become crucial in practical devices.

These important issues will be discussed in the next section, which reports the recent results on depth profiling of carrier concentration and mobility in epitaxial and implanted $\mathrm{SiC}$ materials.

\section{Profiling carrier concentration and mobility in $\mathrm{SiC}$}

Profiling carrier concentration and mobility is fundamental to understand the overall electronic transport properties both of epitaxially grown and ion-implanted semiconductors. To date, most of the studies on carrier concentration and mobility in $\mathrm{SiC}$ have been carried out considering epitaxial substrates, where the carrier concentration is almost constant in depth. However, monitoring also the interfacial properties in epitaxial layers has become crucial to check the abruptness of the changes in concentration, which is particularly critical in some applications requiring the use of very thin epitaxial layers. In the case of ion-implanted materials, conventional "integral" characterization methods (like Hall measurements and sheet resistance measurements [37]) have been mainly employed to determine the average electrical behaviour of the layer. However, in ion-implanted materials, the carrier concentration can be affected by local phenomena, e.g., the precipitation of dopants at the projected ion-range $R_{p}$ in electrically inactive complexes, or the presence of defects acting as compensating centers in the end-of-the range region, close to the junction area (depleted region). The same surface region can be affected by local phenomena influencing mobility and dopant activation.

In this section, the status of depth profiling of carrier concentration and mobility in SiC will be discussed, both for epitaxial and ion-implanted material. These aspects are crucial to predict the device behaviour, particularly in complex devices, where the carrier concentration is modulated in depth and laterally close to surfaces and interfaces.

\subsection{Temperature dependence of carrier concentration and mobility}

Since high-power and high-temperature electronics are the most important fields of application for SiC devices, the knowledge of the temperature behaviour of the electronics properties of the bulk material (epitaxial or implanted) is a fundamental issue.

The temperature dependence of the carrier density and electron mobility in $\mathrm{SiC}$ have been extensively investigated by Hall effect and sheet resistance measurements in epitaxial layers, n-type doped with nitrogen $(\mathrm{N})$ $[73,74]$ and p-type doped with aluminum (Al). $\mathrm{N}$ donors can occupy two different substitutional positions (hexagonal or cubic) in the $\mathrm{C}$ - sublattice, and two different ionization energies are associated to those 
configurations $\left(\Delta E_{h}=62 \mathrm{meV}, \Delta E_{k}=110 \mathrm{meV}\right.$ below the conduction band edge). Two distinct ionization energies have been reported also for $\mathrm{Al}$ acceptors corresponding to two non-equivalent substitutional positions in the $\mathrm{Si}$ sublattice of $4 \mathrm{H}-\mathrm{SiC}$ [75]. The acceptors levels with respect to the valence band $\left(\Delta E_{1}\right.$ and $\left.\Delta E_{2}\right)$ depend on the acceptor concentration $\left(N_{A}\right)$ according to the relation $\Delta E_{i}=\Delta E_{i}^{0}-\alpha N_{A}{ }^{1 / 3}$, where $\Delta E_{1}^{0} \approx 190 \mathrm{meV}$ and $\Delta E_{2}^{0} \approx 230$ $\mathrm{meV}$ and $\alpha \approx 1.9 \times 10^{-5} \mathrm{meV} \times \mathrm{cm}$. Due to the high ionization energies, the hole density at room temperature is only a fraction of the acceptor density.

The mechanisms limiting the electron mobility in $\mathrm{N}$ - doped $4 \mathrm{H}-$ and $6 \mathrm{H}-\mathrm{SiC}$ epi-layers have been investigated in detail as a function of doping concentration and temperature. At room temperature and low concentrations the mobility $\mu$ is limited by intrinsic phonon scattering (acoustic intravalley, intervalley and polar). At carrier densities values larger than $5 \times 10^{16} \mathrm{~cm}^{-3}$ the ionized impurities scattering becomes more important. Finally, at very high electron densities the neutral impurity mode comes into play [76].

Figure 4a reports the temperature dependence of the electron mobility of lightly nitrogen $(\mathrm{N})$ doped $\left(10^{15}-10^{16}\right.$ $\mathrm{cm}^{-3}$ ) $4 \mathrm{H}-$ and $6 \mathrm{H}-\mathrm{SiC}$ epilayers, measured by Hall effect in the standard configuration (magnetic field parallel to c-axis, current parallel to the basal plane) $[73,74]$. In the reported temperature range, intervalley scattering by lattice phonons represents the dominant mechanism limiting in-plane electron mobility in $\mathrm{SiC}$ [73]. On the other hand, the "vertical" drift electron mobility (i.e., along the c-axis) of $4 \mathrm{H}-$ and $6 \mathrm{H}-\mathrm{SiC}$, is important to predict the performances of vertical power devices, and it can be deduced from the temperature dependence of the series resistance in current measurements on Schottky diodes fabricated on $\mathrm{N}$-doped epilayers $[77,78]$. The results are reported in figure $4 \mathrm{~b}$. A dependence of the mobility $\mu$ on the temperature as $T^{-2.1}$ suggests that lattice scattering and material defects are the main limiting factors to the carrier transport in vertical epitaxial devices [77]. It is interesting to observe that the results reported in figures $4 \mathrm{a}$ and $4 \mathrm{~b}$ clearly show the strong anisotropy of the mobility in $6 \mathrm{H}-\mathrm{SiC}$. The fact that the electron mobility depends strongly on the crystallographic direction of travelling carriers is due to the anisotropic structure of conduction bands. In fact, theoretical calculations and experimental data carried out on $6 \mathrm{H}-\mathrm{SiC}$ and $4 \mathrm{H}-\mathrm{SiC}$ revealed that the anisotropy of the mobility values can be ultimately associated to the anisotropy in the effective masses $[79,80]$.

\subsection{Net doping concentration profiles at interfaces between epitaxial layers}

The main requirements on $\mathrm{SiC}$ epitaxial layers for devices applications are the uniformity of the doping concentration together with the abruptness of the junctions between differently doped layers. Since $\mathrm{N}$ donors occupy substitutional positions in the C-sublattice, whereas $\mathrm{Al}$ acceptors in the Si-sublattice, an important parameter influencing the dopant incorporation during epitaxial growth is the $\mathrm{C} / \mathrm{Si}$ ratio. Furthermore, since a background $\mathrm{N}$ concentration is always incorporated during the growth, p-type doping is obtained by overcompensation of $\mathrm{N}$ with Al. When characterizing the uniformity of epitaxial layers, as well as the abruptness of epitaxial p-n junctions, it is crucial to have information on the net doping concentration $\left(N_{A}-N_{D}\right)$ profile, being $N_{A}$ the acceptors and $N_{D}$ the donors concentration. Commonly, secondary ions mass spectrometry (SIMS) is used to obtain the profiles of the atomic concentrations of the doping species. As an example, figure 5a reports the $\mathrm{Al}$ and $\mathrm{N}$ concentration profiles determined by SIMS analysis on a $n^{++} / p^{+} / n$ stack of $4 \mathrm{H}-\mathrm{SiC}$ epilayers [81]. However, SIMS profiling is not able to provide information on the electrical activation of incorporated atoms and on the abruptness of the "electrical" junctions. Recently, scanning probe methods, like scanning capacitance microscopy (SCM), have been applied to address this topic. In SCM measurements, the derivative of capacitance with respect to voltage $(d C / d V)$ is locally detected for each position of the atomic force microscope tip on the cross-sectioned sample surface. The amplitude of the SCM signal is related to the net dopant concentration, whereas its sign is related to the net doping type. Further details on SCM are given in appendix A.2. Figure 5b reports the SCM profile acquired on the same $n^{++} / p^{+} / n$ 4H-SiC multilayer. The comparison between the $\mathrm{Al}$ and $\mathrm{N}$ profiles determined by SIMS (figure 5a) and the SCM profile (figure 5b) indicates that the net doping concentration is uniform within each layer, whereas some fluctuation occurs close to the transitions from one layer to the other. The SCM profile allowed also estimating the abruptness of the transition regions between the differently doped layers, namely the width of the electrical junctions. In the present case, the transition region (indicated by circles in figure $5 \mathrm{~b}$ ) from the $n^{++}\left(N_{D}-N_{A} \approx 1 \times 10^{19} \mathrm{~cm}^{3}\right)$ to the $p^{+}\left(N_{A}-N_{D} \approx 1 \times 10^{18} \mathrm{~cm}^{3}\right)$ doped 
layer and that from the $p^{+}$to the $n\left(N_{D}-N_{A} \approx 2 \times 10^{17} \mathrm{~cm}^{3}\right)$ doped layer are both around 40-60 nm wide. Monitoring the nanoscale properties of the electrical junctions between epilayers can be particularly important to optimize the epilayers growth conditions and/or to understand the electrical behaviour of practical devices.

\subsection{Local carrier concentration and mobility in ion-implanted SiC}

As in the case of Schottky contacts, where the electrical characteristics are influenced by the surface preparation, also the fundamental transport properties in other interfaces are strongly affected by the processing steps employed for device fabrication. Among these processes, ion-implantation is the commonly adopted one to achieve selectively doped regions [2] or to locally tailor the electrical properties of $\mathrm{SiC}$ based devices [82]. In fact, due to the low diffusivity of dopants in $\mathrm{SiC}$ even at high temperatures, such locally doped areas cannot be obtained by conventional diffusion. Multiple implants at different energies and fluencies are commonly carried out to achieve the desired doping profile. During implantation, $\mathrm{SiC}$ substrates are typically kept at temperatures ranging from 300 to $600{ }^{\circ} \mathrm{C}$, to avoid amorphization [83]. Furthermore, high thermal budgets are necessary to achieve the electrical activation of dopants and to recover the lattice damage. Typically, nitrogen (N) or phosphorous (P) implantations are performed to produce low resistivity, n-type SiC regions $[84,85,86,87,88,89]$. Implanted $\mathrm{N}$ atoms tend to be electrically inactive at $\mathrm{N}$ concentration higher than $2-5 \times 10^{19} \mathrm{~cm}^{-3}$ due to the formation of precipitates during post-implantation annealing. However, high donor concentrations are required to reduce the resistivity of Ohmic contacts, as required in the source/drain areas in field-effect transistors (FETs). Under this point of view, $\mathrm{P}$ is used as an alternative donor species with ionization energies close to that of $\mathrm{N}$ donors [88]. Substitutional $\mathrm{P}$ atoms reside also at Si lattice sites. The critical concentration of $2-5 \times 10^{19} \mathrm{~cm}^{-3}$ represents an upper limit for electrically active $\mathrm{N}$ donors, while $\mathrm{P}$ donors can be activated at concentrations above $10^{20} \mathrm{~cm}^{-3}[89]$.

While n-type doped layers with low sheet resistance have been obtained by annealing of $\mathrm{N}$ or $\mathrm{P}$ implanted layers at temperatures from $1300{ }^{\circ} \mathrm{C}[90,91]$ to $1800{ }^{\circ} \mathrm{C}$ [89], efficient p-type doping by $\mathrm{Al}$ and/or B implantation still remains a challenging task $[92,93,94,95,96,97]$. This is due both to intrinsic reasons (the high ionization energies of acceptors [76]) and to the high thermal budgets required by the annealing to achieve the electrical activation of the implanted dopants (i.e. to bring them in the Si-sublattice substitutional positions) and to recover the lattice damage [98]. Different activation ratios $\left(D_{A} / D_{A l}\right.$, with $D_{A}$ the acceptors dose and $D_{A l}$ the implanted Al dose) are reported in literature, depending on the implanted dose, on the target temperature during implantation, and on the post-implantation annealing conditions (temperature, ambient, etc.). In the case of $\mathrm{Al}$ implanted at $650{ }^{\circ} \mathrm{C}$ and annealed at $1670{ }^{\circ} \mathrm{C}, D_{A} / D_{A l}$ values ranging from $50 \%$ to $25 \%$ have been reported for $\mathrm{Al}$ concentrations increasing from $3 \times 10^{18}$ to $10^{21} \mathrm{~cm}^{-3}$ [92]. Saks et al. [96], characterized $\mathrm{Al}$ implants in $4 \mathrm{H}-\mathrm{SiC}$ at concentrations near solubility limit $\left(\sim 2 \times 10^{20} \mathrm{Al} / \mathrm{cm}^{3}\right)$ as a function of the implant and anneal temperatures. For a typical implant temperature of $650^{\circ} \mathrm{C}$, the authors obtained a ratio $D_{A} / D_{A l}$ of $\sim 6 \%-35 \%$ upon post-implantation annealing from 1600 to $1750^{\circ} \mathrm{C}$, respectively. For higher implant temperatures $\left(1000^{\circ} \mathrm{C}\right)$ and for the same postimplantation annealing temperatures $\left(1650-1750^{\circ} \mathrm{C}\right)$, the same authors reported significantly improved $\mathrm{Al}$ activatied fractions approaching the $100 \%$. These results suggest that higher wafer temperatures during Alimplantation should be used during device fabrication, in order to operate with lower post-implantation annealing temperatures and to obtain an almost complete Al-activation. The temperature dependence of the hole mobility in Al-implanted sheets has been investigated in detail in Ref. [76]. As a matter of fact, defects introduced during the implant strongly affect both the electrical activation of Al and the hole mobility. The nature of these defects and their evolution during annealing has been investigated by structural and spectroscopic analyses $[83,99,100]$. In particular, some of those defects, arising from the Al-implant, exhibit a donor like behaviour and compensate the acceptor centers present in the material. These compensating centers strongly affect the transport properties (free hole concentration and mobility) in Al-implanted SiC layers. The density of the compensating centers $\left(N_{D}\right)$ as well as the density of active dopants, are typically obtained fitting temperature dependent measurements of carrier concentration (by Hall effect) with the neutrality equation. These densities are average values over the implanted thickness. However, since the implanted layers are typically obtained from the overlap of several implantation profiles performed with different projected ranges, the integral damage depth profile is expected to be non-uniform and, consequently, also the concentration of compensating centers is 
expected to be dependent on the depth. Recently, the depth distributions of the compensating centers $\left(N_{D}\left(\mathrm{~cm}^{-3}\right)\right)$ and that of the acceptor $\left(N_{A}\left(\mathrm{~cm}^{-3}\right)\right)$ in the implanted sheet have been determined by scanning probe microscopy [101]. SCM was used to obtain the net doping profile $\left(N_{A}-N_{D}\right)$ [102,103], while the resistivity $(\rho)$ profile was obtained by scanning spreading resistance microscopy (SSRM) [101] (details and references for SSRM can be found in appendix A.3). The measured $\rho$ values are related to the local hole concentration $p$ and to the drift mobility $\mu_{p}$, by the relation $\rho=1 /\left(q p \mu_{p}\right)$, where $q$ is the electron charge. On the other hand, the local hole concentration is related to the local densities $N_{A}$ and $N_{D}$ by the neutrality equation:

$$
p+N_{D}=\sum_{n=1}^{2} N_{A, n}\left[1+\frac{p}{g N_{V}} \exp \left(\frac{\Delta E_{A, n}}{k_{B} T}\right)\right]^{-1}
$$

where $N_{A, l}$ and $N_{A, 2}$ are the concentrations of the two $\mathrm{Al}$ acceptor levels (i.e. $N_{A}=N_{A, 1}+N_{A, 2}$ ), $\Delta E_{A, I}$ and $\Delta E_{A, 2}$ are the ionization energies of those levels, $g$ is the degeneracy factor and $N_{V}$ is the effective density of states in the valence band. Inserting the measured local values of $\rho$ and $N_{A}-N_{D}$ in these equations, the profiles of $N_{A}$ and $N_{D}$ and the drift mobility $\left(\mu_{p}\right)$ profile in the implanted layer were determined [101]. Such depth resolved profiles are reported in figure 6 for $4 \mathrm{H}-\mathrm{SiC}$ implanted at $400{ }^{\circ} \mathrm{C}$ with $\mathrm{Al}$ ions at various energies in the range $40-550 \mathrm{keV}$ and subjected to annealing at three different temperatures, $1400{ }^{\circ} \mathrm{C}$ (a), $1500{ }^{\circ} \mathrm{C}$ (b), and $1650{ }^{\circ} \mathrm{C}$ (c) for 30 minutes in $\mathrm{Ar}+\mathrm{SiH}_{4}$ ambient. The multiple implants yield a $\sim 700 \mathrm{~nm}$ thick box-like Al profile $\left(\sim 1 \times 10^{18} \mathrm{~cm}^{-3}\right)$, but the profiles of substitutional $\mathrm{Al}\left(N_{A}\right)$ and of compensating centers $\left(N_{D}\right)$ are strongly non-uniform with respect to depth. After the annealing at $1400{ }^{\circ} \mathrm{C}, N_{D}$ is only slightly lower than $N_{A}$ both in the surface region and in the tail of the profile, thus resulting in a very low net doping concentration and a very high resistivity. After the annealing at $1500{ }^{\circ} \mathrm{C}$ and $1650{ }^{\circ} \mathrm{C}, N_{D}$ becomes a smaller fraction of $N_{A}$ (except in the near-surface region) and this is reflected in an overall decrease of the sheet resistance. In general terms, the thermal evolution of the electrical activation in $\mathrm{Al}$-implanted $4 \mathrm{H}-\mathrm{SiC}$ is the result of a counterbalance between the decrease in the percentage compensation and the increase in the acceptor concentration [101]. The local hole drift mobility $\mu_{p}$ (figure 6d) in the implanted layer decreases with increasing annealing temperatures, due to the increase of the acceptor concentration $N_{A}$.

Typically, as extensively reported in literature, conventional annealing techniques involving horizontal or vertical furnaces (like the results shown in figure 6), lamp annealing systems, etc., are used to achieve electrical activation in ion-doped $\mathrm{SiC}$. Recently, ultra-rapid solid-state microwaves annealing techniques, operating up to $2000^{\circ} \mathrm{C}$, have been proposed to increase the electrical activation of ion-implanted $\mathrm{SiC}$ and to limit the step bunching phenomena [104]. However, these methods still need significant technical improvement to be successfully employed on large area $\mathrm{SiC}$ substrates.

\section{Interface transport properties in the $\mathrm{SiO}_{2} / \mathrm{SiC}$ system}

The progress of SiC-based power switching devices has been fast developing in the field of unipolar devices for blocking voltages in the range $600 \mathrm{~V}-2000 \mathrm{~V}$. Nowadays, Metal-Oxide-Semiconductor Field Effect Transistors (MOSFETs) are the power-switching devices in SiC which are predominantly under development, together with Junction Field Effect Transistors (JFETs). In fact, the performances of SiC MOSFETs in terms of $R_{o n}$ are still far from the theoretical expectations, due to some limitations related to the carrier transport at the $\mathrm{SiO}_{2} / \mathrm{SiC}$ interfaces. On the other hand, JFETs have been proposed as normally-on devices. Although normallyon devices may not be a problem for the most of applications, in some cases normally-off devices are mandatory to guarantee for intrinsic safety conditions.

The complete fabrication of a vertical MOSFET requires ion-implantation for the formation of the n-type source-drain and of the p-type body regions. As discussed in the previous section, these processes involve hightemperature annealing $\left(1400-1800^{\circ} \mathrm{C}\right)$ for electrical activation of the ion-species, which considerably impact on the morphological and electrical properties of the surface and interfaces in the proximity of the channel.

The surface morphology of $4 \mathrm{H}-$ and $6 \mathrm{H}-\mathrm{SiC}$ is typically strongly modified by the high thermal budgets necessary for the electrical activation of implanted dopants. At temperature $>1400{ }^{\circ} \mathrm{C}$ preferential evaporation of $\mathrm{Si}$ from the surface starts to occur. Furthermore, a peculiar roughening of the surface is visible, with the formation of 
large terraces parallel to the original miscut angle ("step bunching"). This step bunching is greatly enhanced in sample regions subjected to high fluence ion-implantation $[105,106]$. As an example, in figure 7 , surface morphology images measured by atomic force microscopy (AFM) are reported in the case of $4 \mathrm{H}-\mathrm{SiC}$ asimplanted with $\mathrm{Al}$ fluence of $1.2 \times 10^{15} \mathrm{~cm}^{-2}$ (figure 7a). The increase of the surface roughness after annealing at $1650{ }^{\circ} \mathrm{C}$ (figure $7 \mathrm{~b}$ ) for $30 \mathrm{~min}$ is evident, as can be seen also from the reported values of the root mean square (RMS) roughness.

The presence of a step bunching can have an influence on some electrical devices parameters, like the contact resistance and the channel channel conductance in SiC MOSFETs. As an example, Lee et al. [107] observed an anisotropy of the drain current in 6H-SiC MOSFETs in the presence of a significant step bunching on the surface oriented along the [1-100] direction. The lower drain current observed when the channel was fabricated with an orientation perpendicular to the step bunching (i.e. along the [11-20] direction) was explained by the different interface roughness appearing to the carriers in the two directions.

Several methods are adopted to reduce roughness, like the use of a graphite capping layer before annealing [108, 109,110] or chemical-mechanical-polishing (CMP) after annealing [111]. As an example, figure 7c shows the morphology of $4 \mathrm{H}-\mathrm{SiC}$ implanted with $\mathrm{Al}$ fluence of $1.2 \times 10^{15} \mathrm{~cm}^{-2}$ and annealed at $1650{ }^{\circ} \mathrm{C}$, after encapsulation in a graphite capping layer. The reduction of the roughening in comparison with $4 \mathrm{H}-\mathrm{SiC}$ annealed under identical conditions without the capping layer (see figure $7 \mathrm{~b}$ ) is evident. In spite of the beneficial effect on the surface roughness of using a capping layer during annealing, it is still not clear if a better morphology systematically results also in an improvement of the channel mobility [112 ].

Beyond the need of a nanometric control of the surface and interface roughness before the gate-oxide formation (which can be achieved e.g. by CMP, capping layers, sacrificial oxidation after activation annealing, etc.), the present serious drawback, hindering the carrier transport in MOS-based SiC devices seems to be the high density of charged states at $\mathrm{SiO}_{2} / 4 \mathrm{H}-\mathrm{SiC}$ interfaces $[113,114,115]$. Several works in the last decades have correlated the microstructure of the $\mathrm{SiO}_{2} / \mathrm{SiC}$ interfaces with the electrical properties of MOS-based devices. Basing on these studies, it is now commonly accepted that the high density of interface traps $D_{i t}$, particularly those located close to the conduction band edge, is responsible for a low effective electron channel mobility in SiC MOSFETs.

Concerning the oxide microstructure, it is known that thermal oxidation of $\mathrm{SiC}$ results in the formation of $\mathrm{SiO}_{2}$ and $\mathrm{CO}$, which diffuses out of the bulk oxide layer. However, residual carbon remains at the interface and can be detrimental for the carrier transport properties in the inversion layer [116]. Hence, the origin of charged traps at the $\mathrm{SiO}_{2} / \mathrm{SiC}$ interface has been associated to interface defects, which are likely related to the presence of residual carbon (graphite-like films, carbon clusters, ....), to silicon suboxide bonds or oxide defects with energy levels inside the $\mathrm{SiC}$ bandgap $[117,118]$. The compositional profile of the thermal oxide on $\mathrm{SiC}$, studied by Vathulya et al. [119] using angle resolved x-ray photoelectron spectroscopy, indicated a direct correlation between the overall carbon content in the oxide and the density of interface states determined by C-V measurements. Accordingly, also Afanas'ev et al. [120] found that the interface states at the $\mathrm{SiO}_{2} / \mathrm{SiC}_{\text {interface }}$ can be associated to the presence of carbon atoms and that removal of the carbon species (i.e., by an UV preoxidation treatment) is beneficial to reduce the interface state density and fixed charges in the MOS capacitors on $\mathrm{SiC}$. A further direct evidence of an accumulation of carbon at the interface between thermally grown $\mathrm{SiO}_{2}$ (formed by wet oxidation at $1100^{\circ} \mathrm{C}$ ) and $\mathrm{SiC}$ was given by Chang et al. [121] combining transmission electron microscopy (TEM) with electron energy loss spectroscopy (EELS). The thickness of these C-rich regions was estimated to be $10-15 \AA$. The absence of carbon at the interface with a deposited oxide on SiC suggested that the carbon accumulation was the result of the oxidation process.

The most reliable approach to partially overcome the problem of a low channel mobility in $\mathrm{SiC}$ MOSFETs is to employ post-oxidation annealing processes of the gate oxide in nitrogen-rich ambient $\left(\mathrm{N}_{2} \mathrm{O}\right.$, $\mathrm{NO}, .$.$) in the temperature range 1100-1300^{\circ} \mathrm{C}$ [114]. In fact, only after such nitridation annealing treatments of the gate oxides values of channel mobility in the range of $30-50 \mathrm{~cm}^{2} \mathrm{~V}^{-1} \mathrm{~s}^{-1}$ could be achieved [114]. As an alternative to the nitridation, other methods have been also studied with the aim to reduce the interface states density in SiC MOSFETs. As an example, ion-implantation has been proposed to introduce nitrogen at the $\mathrm{SiO}_{2} / \mathrm{SiC}$. In fact, performing a thermal oxidation after $\mathrm{N}$-implantation of the $\mathrm{SiC}$ epilayer leads to a reduction of the interface state density $D_{i t}$ in MOS capacitors [122], and to an improvement of the mobility in $4 \mathrm{H}-\mathrm{SiC}$ MOSFETs [123,124]. However, implantation-induced damage remains a serious limitation for the illustrated 
method. Higher values of the channel mobility (up to $154 \mathrm{~cm}^{2} \mathrm{~V}^{-1} \mathrm{~s}^{-1}$ ) were achieved using oxidation processes performed in alumina furnaces [125], but the existence of mobile charge in these oxides prevents practical use of this method for device manufacturing.

The role of nitrogen in the reduction of interface traps density is quite complex and several explanations have been given on the basis of both structural and electrical analysis performed.

The first experiments on nitridation of oxides on $\mathrm{SiC}$ were presented by $\mathrm{Li}$ et al. [126], who observed a reduction of the interface state density at $\mathrm{SiO}_{2} / 6 \mathrm{H}-\mathrm{SiC}$ interfaces after an annealing in $\mathrm{NO}$, with respect to a rapid thermal oxidation process in $\mathrm{O}_{2}$. The beneficial impact of the NO process on the interface state density was generically attributed to a reaction of nitrogen with the silicon dangling bonds during the oxidation. The established improvements of electrical properties of the NO annealed oxides were better explained by Jamet and Dimitrijev [127], who studied the nitridation (in $\mathrm{N}_{2} \mathrm{O}$ and $\mathrm{NO}$ ) by either annealing or direct growth of gate oxides on $4 \mathrm{H} \mathrm{SiC}$. In particular, x-ray photoelectron spectroscopy (XPS) and SIMS depth profiles of nitrogen, revealed a "clean" $\mathrm{SiO}_{2} / \mathrm{SiC}$ interface after $\mathrm{NO}$ and $\mathrm{N}_{2} \mathrm{O}$ processes, while interfaces annealed in Argon exhibited the presence of complex suboxides and oxide-carbon compounds. Furthermore, for nitrided oxides, XPS showed that the complex suboxide and oxide-carbon bonds were removed, thus being accompanied by the formation of strong $S i \equiv N$ bonds and the significant reduction of the spectral intensity of $C-C$ bonds [127]. Mc Donald $e t$ al. [128] studied the reduction of the interface states density by NO-nitridation, observing a saturation effect upon a nitrogen incorporation level of $2.5 \times 10^{14} \mathrm{~cm}^{2}$. The presence of such saturation is consistent with a model of the interface in which large clusters composed of an excess of interfacial carbon or silicon are subsequently passivated (and dissolved) by the indiffusing nitrogen, with the formation of strong $C \equiv N$ and $S i \equiv N$ bonds. Finally, according to the more recent work by Wang et al. [129] the action of nitrogen at the interface can assimilated to that of a positive oxide charge, neutralizing the negatively charged acceptor-like traps commonly present on $4 \mathrm{H}-\mathrm{SiC}$ surfaces and forming charge dipoles at the $\mathrm{SiO}_{2} / 4 \mathrm{H}-\mathrm{SiC}$ interface.

Recent works by Zheleva et al. [130] and by Biggerstaff et al. [131], based on a nanoscale characterization using high resolution TEM and EELS, definitively correlated the existence of a "transition layer" on both sides of the $\mathrm{SiO}_{2} / \mathrm{SiC}$ interface with the electrical properties of the $\mathrm{SiO}_{2} / \mathrm{SiC}$ interface. In particular, the structural degradation (amorphization) observed in the top few atomic layers of $\mathrm{SiC}$ and the presence of this interfacial transition region was associated to changes in the $\mathrm{SiO}_{2}$ and $\mathrm{SiC}$ stoichiometry. A detailed chemical analysis indicated the formation of a silicon-oxycarbide layer $\left(\mathrm{SiC}_{x} \mathrm{O}_{y}\right)$, where the layer on the $\mathrm{SiO}_{2}$ side contains $\mathrm{C}$, whereas the top layer of $\mathrm{SiC}$ contains excess $\mathrm{C}$ and small amounts of $\mathrm{O}$ [130]. This nanometric transition layer is something inherent to the $\mathrm{SiO}_{2} / \mathrm{SiC}$ interface, as it is always present at the interface independent of the processing condition of the oxide. However, the thickness of the transition layer can be partially reduced, even if not completely removed, by $\mathrm{N}$ incorporation by post-annealing treatments [132]. It is worth noting that the width of this transition layer is strongly correlated with the values of the effective channel mobility. Figure 8 reports the peak effective channel mobility and the interface trap density, measured on fully processed $4 \mathrm{H}-\mathrm{SiC}$ MOSFET devices [131], as a function of the transition layer thickness. As can be seen, the channel mobility decreases almost linearly with increasing the thickness of this transition layer. Notably, the increase of the transition layer thickness is also correlated to the increase of the interface trap density $D_{i t}$.

Another important concern for dielectric/SiC interfaces is the long-time electrical reliability of the dielectric itself. Even if the used materials can be the identical in $\mathrm{SiC}$ and $\mathrm{Si}$ MOS systems (e.g., $\mathrm{SiO}_{2}$ ), due to the large band gap of $\mathrm{SiC}$ the conduction band offset between the $\mathrm{SiC}$ substrate and $\mathrm{SiO}_{2}$ is smaller than in the case of the $\mathrm{SiO}_{2} / \mathrm{Si}$ system. Hence, similar MOS systems in $\mathrm{SiC}$ typically exhibit a much higher tunnelling current than in Si under similar applied electric fields. This latter, in turn, can contribute significantly to the charge to breakdown, limiting the temperature performance of the oxide. Furthermore, as mentioned before, the oxidation of $\mathrm{SiC}$ involves the oxygen in-diffusion and the subsequent binding of $\mathrm{O}$ atoms to the $\mathrm{Si}$ atoms. Simultaneously, residual $\mathrm{C}$ can be released either as $\mathrm{CO}$ gaseous compounds at the oxide surface, otherwise form graphite, or interstitial defects at the interfaces [116,117,118,119,120,121,130] according to a balance between the oxidation rate and the $\mathrm{C}$ solubility. Considering these intrinsic differences, it is important to accurately assess the reliability of the $\mathrm{SiO}_{2} / \mathrm{SiC}$ system at a nanoscale level, in order to establish a comparison (analogies and differences) with the case of $\mathrm{Si}$, i.e., whose technology for MOSFETs devices is already well consolidated. In this context, Fiorenza et al. $[133,134]$ investigated the reliability of thermal oxide grown on $4 \mathrm{H}-\mathrm{SiC}$, determining the Weibull statistics mapping the oxide local failure (pre-breakdown hot-points) at a nanoscale by using an 
original C-AFM based method to provide a local voltage stress. While for thinner thermal oxides (up to 5-7 nm) an intrinsic behaviour according to the ideal percolation model in $\mathrm{SiO}_{2}$ was found, significant deviations from the theory were observed in the case of thicker $(>10 \mathrm{~nm}) \mathrm{SiO}_{2}$ layers. Since the Weibull theory includes only the defects inside the oxide, this behaviour can be related to the presence of $\mathrm{C}$ inside the $\mathrm{SiO}_{2}$ layer, i.e., namely to the previously described transition layer. In particular, the presence of a defective transition region in the oxide, whose thickness depends on the oxidation conditions and increases for thicker thermal oxides [131, 135], can enhance the intrinsic defect formation probability.

All the above recent insights gained on the nanoscale electro-structural properties of the $\mathrm{SiO}_{2} / \mathrm{SiC}$ interfaces are the fundamental starting point to predict the carrier scattering in the inversion layer and the breakdown phenomena, and, eventually, to approach with novel solutions (new dielectrics, new oxidation procedures, etc.) the present drawbacks in SiC MOSFETs.

\section{Interfaces considering different $\mathrm{SiC}$ polytypes}

As pointed out in the previous sections, to date the vast majority of $\mathrm{SiC}$ devices and applications have been implemented using the two stable hexagonal polytypes $(4 \mathrm{H}, 6 \mathrm{H})$. However, several properties make 3C$\mathrm{SiC}$ unique among $\mathrm{SiC}$ polytypes, such as high low-field mobility, low ionization energy for the nitrogen donor levels, isotropic electrical and thermochemical properties, etc.[136]. Furthermore, 3C-SiC is expected to give a better $\mathrm{SiO}_{2} / \mathrm{SiC}$ interface in terms of inversion channel mobility $[137,138]$. In fact, since the bottom of the conduction band in $3 \mathrm{C}-\mathrm{SiC}$ is about $0.9 \mathrm{eV}$ lower than in $4 \mathrm{H}-\mathrm{SiC}$, the near-interface traps located close to the bottom of the conduction band in $4 \mathrm{H}-\mathrm{SiC}$, should be inactive in $3 \mathrm{C}-\mathrm{SiC}$, leading to higher inversion channel mobility $[113,114]$.

Unfortunately, the possibility to grow high-quality single crystalline $3 \mathrm{C}-\mathrm{SiC}$ films on large area $\mathrm{Si}$ substrates is strongly limited by the high lattice mismatch $(20 \%)$, and the mismatch in the thermal expansion coefficients $(8 \%)$ between $3 \mathrm{C}-\mathrm{SiC}$ and $\mathrm{Si}$, leading to interfacial strain during the processes of growth and cooling down. Hence, a large variety of defects are formed both at the interface and in the films, as misfit dislocations, stacking faults, twinning rotations, voids, anti-phase domains, etc. [139], making this material unsuitable for devices fabrication. Due to these limitations, for a while $3 \mathrm{C}-\mathrm{SiC}$ has been defined as the "forgotten polytype" [136].

A significant progress was achieved during the last few years, when single crystalline $3 \mathrm{C}$-SiC material with a lower defect density, obtained starting the growth process from an "undulant" Si substrate, has been demonstrated, showing a potential impact for vertical power devices onto large-diameter wafers [140]. As a matter of fact, using such "free-standing" material, values of channel mobility up to $260 \mathrm{~cm}^{2} / \mathrm{Vs}$ could be obtained in 3C-SiC vertical MOSFETs [141]. Considering the higher channel mobility with respect to 4H-SiC and the recent progresses in the growth of large area free standing substrates of good quality, 3C-SiC has been indicated as the polytype of choice for medium voltage (600 V to $1200 \mathrm{~V})$ vertical MOSFETs, in spite of the lower critical electric field of this polytype [142].

In principle, a combination of $3 \mathrm{C}-\mathrm{SiC}$ with different polytypes (like the hexagonal ones) is particularly interesting because their different electronic structures could allow the spatial confinement of carriers in quantum wells. However, for many years the formation of such heterostructures has been limited by the high defect density resulting from the heteropolytypical growth. A critical problem in the growth of $3 \mathrm{C}-\mathrm{SiC} / \alpha-\mathrm{SiC}$ heterostructures is the occurrence of incoherent twin boundaries, i.e., the so called double positioning boundaries (DPB). DBPs are formed when $3 \mathrm{C}-\mathrm{SiC}$ islands of different orientation (rotated by $60^{\circ}$ with respect to each other) nucleate and subsequently expand and meet during growth [143]. Hence, the growth of SiC heteropolytypic structures requires well definite conditions (i.e., temperature, $\mathrm{C} / \mathrm{Si}$ ratio, etc.) in order to control the crystalline quality of each polytype forming the structure.

The first demonstration of good quality heteropolytypic SiC structures was given by Fissel [144] using solid-source molecular beam epitaxy. Pseudomorphic 3C-SiC layers were grown on $\alpha$-SiC; they were unintentionally doped (as deduced by optical measurements) and nearly free of twins. Furthermore, the growth of other $4 \mathrm{H} / 3 \mathrm{C} / 4 \mathrm{H}$ heterostructures was also demonstrated, whose optical properties could be explained on the basis of theoretical calculations of the band structure of such systems [145,146]. 
Recently, theoretical and experimental works on heterojunctions formed between cubic (3C) and hexagonal $(6 \mathrm{H}, 4 \mathrm{H}) \mathrm{SiC}$, opened new prospects for 3C-SiC for high-frequency devices. In particular, the formation of a two-dimensional electron gas (2DEG) at the heterointerface has been theoretically predicted by Polyakov and Schwierz [147], by numerical self-consistent solving the Schrödinger-Poisson equations in the $4 \mathrm{H} / 3 \mathrm{C} \mathrm{SiC}$ and $6 \mathrm{H} / 3 \mathrm{C} \mathrm{SiC}$ systems. The results of these calculations predicted the formation of a 2DEG with a sheet carrier density $n_{s}$ in the range of $0.8-1.3 \times 10^{13} \mathrm{~cm}^{-2}$, i.e., of the same order of magnitude of the values found in GaN-based heterojnctions, thus being particularly interesting for fabricating high electron mobility transistors (HEMTs) using a complete SiC technology.

Basing on these theoretical predictions, the electronic properties of $\mathrm{SiC}$ heteropolytype junctions, in which a 3C-SiC layer was grown either on the $\mathrm{C}$ - or on the Si-terminated face of hexagonal SiC, were recently investigated by Chandrashekhar et al. [148,149] using capacitance-voltage (C-V) and Hall measurements. Following these studies, a 2DEG was experimentally observed for the first time in 3C-SiC/6H-SiC (C-face) heterostructures [150]. Figure 9 shows the electron distribution at the heterointerface as a function of the depth, determined by $\mathrm{C}-\mathrm{V}$ analysis. The peak located at a depth of $32 \mathrm{~nm}$, i.e. the position of the $3 \mathrm{C}-\mathrm{SiC} / 6 \mathrm{H}-\mathrm{SiC}$ interface, indicates the formation of the 2DEG. The peak electron density is as high as $4 \times 10^{19} \mathrm{~cm}^{-3}$, giving a sheet charge density of $2.5 \times 10^{12} \mathrm{~cm}^{-2}$. A schematic band diagram of the $3 \mathrm{C}-\mathrm{SiC} / 6 \mathrm{H}-\mathrm{SiC}$ heterointerface is also reported in the inset. It must be pointed out that this result could be achieved thanks to high quality $3 \mathrm{C}-\mathrm{SiC}$ heteroepitaxial layers grown on the $\mathrm{C}$-face of a $6 \mathrm{H}-\mathrm{SiC}$ buffer layer. However, typically 3C-SiC grown onto hexagonal substrates $(6 \mathrm{H}, 4 \mathrm{H})$ is characterized by a large variety of defects, like misfit dislocations, stacking faults, double positioning boundaries (DPBs) and microtwins [143]. Clearly, in the presence of such a large variety of defects, the control of metal/3C-SiC interfaces becomes critical.

In this context, to fully exploit the potentiality of cubic $\mathrm{SiC}$ for devices, the development of reliable Schottky contacts, with a high barrier height and low leakage currents, still represents a big challenge. Such contacts, in fact, should be required for modulating the sheet charge density inside a 2DEG channel in a transistor. The typical values of the $\mathrm{SBH}$ on $3 \mathrm{C}-\mathrm{SiC}$ however are in the range of $0.4-0.7 \mathrm{eV}$ (see table 2), i.e., below the theoretical values expected considering the 3C-SiC band-gap. This long standing fundamental topic was recently addressed by Eriksson et al. [151], who analyzed the electrical characteristics of Au/3C-SiC Schottky barriers as a function of contact area, establishing a correlation between the Schottky barrier and the material defects. Figure 10a reports the I-V characteristics acquired by means of C-AFM on Schottky contacts fabricated on a region containing DPB or on a DPB-free region. As can be seen, DPBs are "killer defects" for metal/3C-SiC Schottky contacts, since in the presence of a DPB the Au/3C-SiC contact exhibit an Ohmic rather than a rectifying behaviour. Furthermore, restricting the study to DPB-free regions, I-V measurements showed an increase of the SBH with decreasing the contact area, as reported in figure 10b. In particular, by reducing the contact size down to $5 \mu \mathrm{m}$ in diameter, the value of $\Phi_{B}$ becomes closer to the ideal barrier height of Au on 3C$\mathrm{SiC}$ [151]. An analytical model to describe the dependence of $\Phi_{B}$ on the defect density was proposed, and fits well the experimental results (see figure 10b). Details on this model are reported in Ref. [151]. These results suggest that, beyond the surface conditions (chemistry, interface index, ...), specific polytype defects also play a crucial role in the formation of Schottky barriers on 3C-SiC. Hence, with the present available material quality, the main applications of $3 \mathrm{C}-\mathrm{SiC}$ remain in the field of sensors and micro electro mechanical systems (MEMS).

\section{Summary and Outlook}

In this paper, some relevant nanoscale aspects of carrier transport in $\mathrm{SiC}$ materials and devices were reviewed. They are playing an increasing importance along with the crucial role provided by interfaces in current $\mathrm{SiC}$ technology. Clearly, although the significant progresses achieved in the last years in the material quality and device processing opened significant perspectives for $\mathrm{SiC}$, several scientific open issues related to the transport properties still remain. Hence, for a further development of $\mathrm{SiC}$ technology, significant efforts in fundamental research are required to better understand the transport phenomena, where a nanoscale approach appears to be mandatory.

The lateral inhomogeneity of Schottky barrier is mainly associated to the device processing even if the material quality can still play a significant role. The degree of homogeneity of Schottky barriers in SiC, that is critical for a family of devices, can be significantly improved by employing appropriate metallization schemes, 
post-deposition annealing or sacrificial oxidation steps. The use of nickel silicides as Schottky metal, having a higher reproducibility of the electrical characteristics, can be an interesting alternative to other metals for high temperature applications or radiation and/or light detectors.

Profiling carrier concentration and mobility is fundamental to understand the overall electronic transport properties of either epitaxial or ion-implanted SiC materials. Particularly interesting for devices is the case of ion-implanted material, in which the carrier concentration and mobility can be locally dependent on the ioninduced damage, e.g., by the precipitation of dopants in electrically inactive complexes, or by the presence of defects acting as compensating centers. The high temperatures required for implant activation lead to a high surface roughness and significant step bunching. In this sense, the nanoscale control of surface and interface properties by novel encapsulation and/or polishing techniques, and the development of ultra-rapid annealing steps are current subjects of investigations.

In the case of $\mathrm{SiO}_{2} / \mathrm{SiC}$ interfaces, crucial for MOSFETs devices, the channel mobility is typically limited in the range $30-50 \mathrm{~cm}^{2} / \mathrm{Vs}$ due the presence of a high interface state density. The high interface states density is correlated to the existence of a transition layer, which is intrinsic in the nature of the $\mathrm{SiO}_{2} / \mathrm{SiC}$ interface. The control of surface and interfaces during annealing and gate-oxidation is fundamental, even if a real technological breakthrough in the nanoscale control of $\mathrm{SiO}_{2} / \mathrm{SiC}$ interface state density seems to be required to increase the channel mobility values. The use of other dielectric/SiC interfaces and/or non-conventional oxidation techniques should be considered to overcome the present physical limitations of the $\mathrm{SiO}_{2} / \mathrm{SiC}$ system.

Finally, due to the crystalline quality of the available $\mathrm{SiC}$ materials, applications in power electronics are still restricted to the hexagonal polytypes, where the use of cubic 3C-SiC seems at the moment to be limited to the field of sensors and MEMS, in spite of the promising results obtained recently on heteropolytype 3C$\mathrm{SiC} / 6 \mathrm{H}-\mathrm{SiC}$ interfaces.

\section{Acknowledgments}

The authors would like to thank all the colleagues of CNR-IMM in Catania who contributed to achieve the reported results. In particular, they are grateful to R. Lo Nigro, P. Fiorenza, A. Sciuto, F. Iucolano, M-H. Weng and J. Eriksson for the fruitful scientific collaboration during the last years. S. Di Franco is acknowledged for his valuable technical support during sample preparation.

This work was partially supported by ST Microelectronics Catania, by the FIRB project RBIP068LNE_001 of the Italian Ministry for Research, and by the by European Commission in the framework of the MANSiC project (MRTN-CT-2006-035735).

\section{Appendix}

\section{A.1. Schottky barrier height mapping with nanoscale resolution}

Ballistic electron emission microscopy (BEEM) [51], the first demonstrated method for local mapping of metalsemiconductor Schottky barrier height ( $\mathrm{SBH}$ ), is based on the tunnel injection of hot electrons from the reverse biased tip of a scanning tunneling microscope (STM) to the metal film. If the film thickness is comparable or lower than the electron mean free path in the metal, a significant fraction of the hot electrons propagate ballistically through it. When a bias higher than a threshold value $V_{t h}=\Phi_{B} / q$ (with $\Phi_{B}$ the SBH and $q$ the electron charge) is applied to the tip, the ballistic electrons are able to overcome the barrier, propagate in the semiconductor and a current is collected at the backcontact. A SBH map is obtained by measuring the threshold voltage for each tip position on the metal. Although BEEM proved a high spatial and energy resolution, it suffers the intrinsic limitations of STM. In fact, since the injected tunnel current intensity is used also in the tip-height control feedback, BEEM cannot be applied to samples containing both conductive and insulating regions on the surface. Moreover, the BEEM current, i.e., the fraction of the injected current propagating ballistically in the metal film, is typically very low (in the order of the pA, with a high noise level). 
Lately, an alternative approach based on conductive atomic force microscopy (C-AFM) was demonstrated [62], which overcomes some of the BEEM limitations. Scanning a forward biased C-AFM tip in contact on an ultrathin $(<5 \mathrm{~nm})$ metal film, current flows only through a very localized region (in the order of the tip diameter) of the macroscopic metal-semiconductor contact, i.e., a "nano-Schottky diode" is formed point by point. This localization of the current is due the electrons propagating ballistically in the direction perpendicular to the ultrathin metal film, whereas they encounter a high-resistivity in the direction parallel to the interface. For such measurements, the back side Ohmic contact of the semiconductor is connected to a current amplifier enabling the detection of currents on the nA scale with a pA sensitivity. In this way, two-dimensional maps of the SBH can be extracted from the current-voltage characteristics collected for different tip positions. The lateral resolution of the method is $10-20 \mathrm{~nm}$ and the energy resolution is in the $0.1 \mathrm{eV}$ range.

For some specific applications, the C-AFM-based approach is more suitable than BEEM. In fact, since it is based on "contact mode" AFM, the feedback for the tip height position is based on the cantilever deflection. This latter allows to characterize also samples containing both conductive and insulating regions on the surface. Moreover, the collected current values are typically in the order of the nA, i.e. 2-3 orders of magnitude higher than BEEM currents.

\section{A.2. Scanning Capacitance Microscopy (SCM)}

Scanning capacitance microscopy (SCM) is based on the use of a conductive AFM tip, connected to a high sensitivity capacitance sensor. The probe is scanned in contact mode on the surface of a semiconductor coated by an ultra-thin (a few $\mathrm{nm}$ ) insulating film, thus forming a nanometric metal-insulator-semiconductor (nanoMIS) device. During the measurement, the sample is biased by a DC bias and a high frequency $(\sim 100 \mathrm{kHz})$ small amplitude AC bias. A high sensitivity capacitance sensor connected to the probe measures the capacitance variations induced in the nanoMIS structure by the modulating AC bias. Due to the nanoscale dimensions of the system, these capacitance variations are in the order of the attoF $\left(10^{-18} \mathrm{~F}\right)$ or sub-attoF. The capacitance sensor in the state of the art SCM equipments is based on the RCA video disc capacitive-pickup circuitry, working at 900$1000 \mathrm{MHz}$ with a sensitivity from $\sim 10^{-19}$ to $\sim 10^{-21} \mathrm{~F} \times \mathrm{Hz}^{-1 / 2}$. Since the stray capacitances are several orders of magnitude larger (in the order of $\mathrm{pF}$ ) than the tip/sample capacitance, the small capacitance variations of the "nanoMIS" system are extracted filtering the sensor output by a lock-in amplifier, locked at the modulating AC bias frequency. The lock-in output is an arbitrary units (a.u.) signal proportional to the derivative of capacitance with respect to voltage $(d C / d V)$ of the nanoMIS.

A SCM map is formed by a 2D array of $\mathrm{dC} / \mathrm{dV}$ values measured at the fixed DC bias applied to the sample. The $\mathrm{DC}$ bias is usually fixed on the peak of the $\mathrm{dC} / \mathrm{dV}$ curve, corresponding to the flatband voltage condition of the nanoMIS. The capacitance variations are mainly related to the local net doping concentration underneath the tip. According to the MIS theory, the $d C / d V$ sign is negative for p-type doped and positive for n-type doped semiconductors, thus enabling to distinguish between different type doped areas. Moreover, the absolute value of the $\mathrm{dC} / \mathrm{dV}$ curve peak decreases monotonically with increasing the net doping concentration concentration. The relation between the $d C / d V$ signal and the net doping concentration is typically experimentally determined using dedicated calibration samples [152].

Both the case of $\mathrm{Si}$ and of $\mathrm{SiC}$ [103], a high sensitivity $(\sim 10 \%)$ on a wide doping concentration range (from $\sim 10^{15}$ to $\sim 10^{20} \mathrm{~cm}^{-3}$ ) has been demonstrated on dedicated $\mathrm{p}$-and $\mathrm{n}$-type calibration samples. This range is limited at the highest concentrations $\left(>10^{20} \mathrm{~cm}^{-3}\right)$, due to the very small capacitance variations, i.e. no depletion region is formed in the semiconductor. For the lowest concentrations $\left(<10^{15} \mathrm{~cm}^{-3}\right)$ the sensitivity is limited by oxide fixed and trapped charges and oxide-semiconductor interface states. The nanometric depth resolution of this method has been demonstrated on dedicated $\mathrm{Si}$ and SiGe test structures [152,153].

\section{A.3. Scanning Spreading Resistance Microscopy (SSRM)}

In scanning spreading resistance microscopy (SSRM) a hard conductive AFM probe (typically a diamond coated tip) is scanned in contact mode across the sample, while a DC bias is applied between an Ohmic contact on the back-side of the sample and the tip. The current flowing between the tip and the back-side is measured using a logarithmic current amplifier with a typical range from $1 \mathrm{pA}$ to $1 \mathrm{~mA}$. The total measured resistance R in SSRM 
experiments includes the resistance of the probe $R_{\text {tip }}$, the tip-semiconductor contact resistance $R_{\text {contact }}$, the spreading resistance $\mathrm{R}_{\text {spread }}$ encountered by the current flowing from the nanometric contact to the semiconductor, the sample series resistance $R_{\text {series }}$ and the back-contact resistance $R_{\text {back. }}$. When a pressure in the order of GPa (corresponding to a $\mu \mathrm{N}$ force on a contact surface of $\sim 10 \mathrm{~nm}$ radius) is applied between the conductive tip and the semiconductor sample, a very stable electrical contact is tipically established. In fact, the native oxide on the semiconductor surface is pushed through and, in same cases (like for $\mathrm{Si}$ ), the large pressure can be responsible of local changes of the electronic properties (from a semiconducting to a conducting phase), due to elasto-plastic or even fully plastic deformations of the in indented sample region. Under these conditions, the measured resistance $\mathrm{R}$ is dominated by the spreading resistance contribution $\mathrm{R}_{\text {spread }}$, which, in the first approximation, is linearly related to the local semiconductor resistivity $\rho$ by $\mathrm{R}_{\text {spread }}=\rho / 4 \mathrm{a}$, being $a$ the "effective contact radius". In the practical cases, however, this relation is experimentally determined using dedicated calibration samples. The resistivity is, in turns, related to the carrier concentration $n$ and to the carrier mobility $\mu$ as $\rho=1 /(\mathrm{qn} \mu)$.

To date, SSRM has been applied both to Si [154], Ge, SiGe [153], III-V semiconductors (GaAs, InP) [155] and $\mathrm{SiC}$ [101]. Similarly to SCM, SSRM benefits from an extremely large dynamic range (from $10^{15}$ to $10^{20} \mathrm{~cm}^{-3}$ ). This range is limited at the high carrier concentration $\left(>10^{20} \mathrm{~cm}^{-3}\right)$ by the presence of the diamond probe resistance in series with the spreading resistance. In low doped areas $\left(<10^{15} \mathrm{~cm}^{-3}\right)$, the SSRM measurements are disturbed by the presence of surface charges. 
Table 1. Physical properties of the most common SiC polytypes. For comparison, the properties of $\mathrm{Si}$ are also reported.

\begin{tabular}{|l|l|l|l|l|}
\hline Property & $\mathbf{S i}$ & 3C-SiC & 6H-SiC & 4H-SiC \\
\hline Bandgap $(\mathrm{eV})$ & 1.12 & 2.35 & 3.08 & 3.28 \\
\hline $\begin{array}{l}\text { Breakdown field } E_{B}(\mathrm{MV} / \mathrm{cm}) \\
\left(\text { at } N_{D}=5 \times 10^{15} \mathrm{~cm}^{-3}\right)\end{array}$ & 0.3 & 1.5 & 2.2 & 2.3 \\
\hline $\begin{array}{l}\text { Intrinsic carrier concentration } n_{i}\left(\mathrm{~cm}^{-3}\right) \\
(\text { at } T=300 \mathrm{~K})\end{array}$ & $1 \times 10^{10}$ & $1.5 \times 10^{-1}$ & $1.6 \times 10^{-6}$ & $5 \times 10^{-9}$ \\
\hline Electron mobility $\mu_{n}\left(\mathrm{~cm}^{2} / \mathrm{Vs}\right)$ & 1350 & 900 & 370 & 800 \\
\hline Hole mobility $\mu_{h}\left(\mathrm{~cm}^{2} / \mathrm{Vs}\right)$ & 480 & 40 & 80 & 120 \\
\hline Saturated electron velocity $v_{s}\left(10^{7} \mathrm{~cm} / \mathrm{s}\right)$ & 1 & 2 & 2 & 2 \\
\hline Thermal conductivity $\kappa(\mathrm{W} / \mathrm{cmK})$ & 1.5 & 4.9 & 4.9 & 4.9 \\
\hline Dielectric constant $\mathcal{E}$ & 11.8 & 9.6 & 9.7 & 9.7 \\
\hline Electron affinity $\chi_{s}(\mathrm{eV})$ & 4.05 & 3.8 & 3.3 & 3.1 \\
\hline
\end{tabular}


Table 2. Schottky Barrier Height values for different metals on n-type 3C-SiC, $6 \mathrm{H}-\mathrm{SiC}$ and $4 \mathrm{H}-\mathrm{SiC}$. The values were determined by I-V measurements in Schottky diodes. For the hexagonal polytypes, they are referred to the Si-terminated face.

\begin{tabular}{|l|l|l|}
\hline 3C-SiC & SBH $(\mathrm{eV})$ & Ref. \\
\hline & & \\
\hline $\mathrm{Ti}$ & $0.40 \mathrm{eV}$ & {$[16]$} \\
\hline $\mathrm{Ni}$ & $0.56 \mathrm{eV}$ & {$[16]$} \\
\hline $\mathrm{Au}$ & $0.47 \mathrm{eV}$ & {$[17]$} \\
\hline $\mathrm{Au}$ & $0.67 \mathrm{eV}$ & {$[16]$} \\
\hline $\mathrm{Pt}$ & $0.85 \mathrm{eV}$ & {$[18]$} \\
\hline & & \\
\hline $\mathbf{6 H}-\mathrm{SiC}$ & $\mathrm{SBH}(\mathrm{eV})$ & Ref. \\
\hline & & \\
\hline $\mathrm{Al}$ & 0.26 & {$[19]$} \\
\hline $\mathrm{Ag}$ & 0.83 & {$[20]$} \\
\hline $\mathrm{Ti}$ & 0.76 & {$[21]$} \\
\hline $\mathrm{Ti}$ & 0.93 & {$[22]$} \\
\hline $\mathrm{Ti}$ & 0.96 & {$[23]$} \\
\hline $\mathrm{Ni}$ & 1.08 & {$[23]$} \\
\hline $\mathrm{Ni}$ & 1.24 & {$[19]$} \\
\hline $\mathrm{Ni}$ & 1.29 & {$[24]$} \\
\hline $\mathrm{Ni}{ }_{2} \mathrm{Si}$ & 1.39 & {$[22]$} \\
\hline $\mathrm{Cu}$ & 1.18 & {$[23]$} \\
\hline $\mathrm{Au}$ & 1.41 & {$[23]$} \\
\hline $\mathrm{Pd}$ & 1.21 & {$[25]$} \\
\hline $\mathrm{Pt}$ & 1.04 & {$[26]$} \\
\hline & & \\
\hline $\mathbf{4 H}-\mathrm{SiC}$ & $\mathrm{SBH}(\mathrm{eV})$ & $\mathrm{Ref}$. \\
\hline & & \\
\hline $\mathrm{Mo}$ & 1.04 & {$[27]$} \\
\hline $\mathrm{Mo}$ & 1.11 & {$[28]$} \\
\hline $\mathrm{W}$ & 1.17 & {$[28]$} \\
\hline $\mathrm{Ta}$ & 1.10 & {$[29]$} \\
\hline $\mathrm{Ti}$ & 1.23 & {$[22]$} \\
\hline $\mathrm{Ti}$ & 1.27 & {$[30]$} \\
\hline $\mathrm{TiW}$ & 1.22 & {$[31]$} \\
\hline $\mathrm{Ni}$ & 1.32 & {$[32]$} \\
\hline $\mathrm{Ni}$ & 1.44 & {$[33]$} \\
\hline $\mathrm{Ni}{ }_{2} \mathrm{Si}$ & 1.60 & {$[34]$} \\
\hline $\mathrm{Au}$ & 1.73 & {$[35]$} \\
\hline $\mathrm{Pt}$ & 1.39 & {$[36]$} \\
\hline & & \\
\hline & & \\
\hline
\end{tabular}




\section{FIGURE CAPTIONS}

Figure 1. Schottky barrier height $\Phi_{B}$ as a function of the metal work function $\Phi_{m}$ for different metals on 3C-SiC (open squares), $6 \mathrm{H}-\mathrm{SiC}$ (solid circles) and $4 \mathrm{H}-\mathrm{SiC}$ (open triangles). The values of $\Phi_{B}$ (taken from Table 1) are determined from I-V measurements of Schottky diodes on n-type SiC. For the hexagonal polytypes, the Schottky contacts were formed on the Si-face.

Figure 2. Ideality factor $n$ (solid circles) and Schottky barrier height $\Phi_{B}$ (open triangles) as a function of measurement temperature for $\mathrm{Ni}_{2} \mathrm{Si} / 4 \mathrm{H}-\mathrm{SiC}$ Schottky contacts. The inset shows the correlation plot $\Phi_{B}$ vs $n$. The extrapolation of the barrier height at $\mathrm{n}=1$ gives the values of the "homogeneous" $\mathrm{Ni}_{2} \mathrm{Si} / 4 \mathrm{H}-\mathrm{SiC}$ barrier, $\Phi_{B 0}=1.69$ $\mathrm{eV}$ (data from Ref. [34]) .

Figure 3. Distribution of the local Schottky barrier height values (determined by C-AFM) for Au/ $6 \mathrm{H}-\mathrm{SiC}$ contacts, with and without an interfacial non-uniform oxide layer (data from Ref. [62]) .

Figure 4. Temperature dependence of the electron mobility of lightly $\mathrm{N}$ doped $\left(3 \times 10^{15}-1 \times 10^{16} \mathrm{~cm}^{-3}\right) 6 \mathrm{H}-($ solid circles) and $4 \mathrm{H}-\mathrm{SiC}$ (open triangles). (a) In-plane mobility by Hall effect measurements (data from Refs. 73 and 74) and (b) c-axis (vertical) drift mobility by I-V measurements on Schottky diodes (data from Refs. [77] and [78])

Figure 5. (a) Profiles of the concentrations of Nitrogen (solid line) and Aluminium (dashed line) atoms in a $n^{++} / p^{+} / n$ stack of $4 \mathrm{H}-\mathrm{SiC}$ epilayers measured by secondary ions mass spectrometry (SIMS). (b) Scanning capacitance microscopy profile (SCM) acquired on a cross section of the same sample, giving information on the net doping concentration and the doping type. The variations of the doping at the interfaces between the epilayers are marked by the cricles (data from Ref. [81]).

Figure 6. (a-c) Concentration profiles of acceptors $N_{A}$ (solid lines) and compensating donors $N_{D}$ (dashed lines) for the samples annealed at $1400{ }^{\circ} \mathrm{C}, 1500{ }^{\circ} \mathrm{C}$ and $1650{ }^{\circ} \mathrm{C}$ for $30 \mathrm{~min}$. (d) Hole mobility profile determined from the $N_{A}$ and $N_{D}$ profiles for the samples annealed at the three temperatures, $1400^{\circ} \mathrm{C}$ (dot line), $1500^{\circ} \mathrm{C}$ (dashed line) amd $1650^{\circ} \mathrm{C}$ (solid line).

Figure 7. AFM surface morphology on $\mathrm{Al}$ implanted $4 \mathrm{H}$-SiC (fluence $1.2 \times 10^{15} \mathrm{~cm}^{-2}$ ). As-implanted (a), annealed at $1650{ }^{\circ} \mathrm{C}$ for 30 min without (b) and with a graphite capping layer (c). The measured surface root mean square (RMS) roughness is also reported. (data extracted from Refs. [106,110]).

Figure 8. Inversion channel mobility $(\mu)$ (solid squares) and interface traps density $\left(D_{i t}\right)$ (open triangles) as a function of the transition layer thickness. The parameters were determined from the characteristics of $4 \mathrm{H}-\mathrm{SiC}$ MOSFETs (Data extracted from Refs. [130,131]).

Figure 9. Electron density as a function of the depth in 3C-SiC/6H-SiC heterojunction. The presence of a peak located at a depth of around $32 \mathrm{~nm}$ indicates the formation of a 2DEG (data from Ref. [150]). The inset shows a schematic band diagram of the $3 \mathrm{C}-\mathrm{SiC} / 6 \mathrm{H}-\mathrm{SiC}$ system.

Figure 10. (a) $\mathrm{I}-\mathrm{V}$ curves of $\mathrm{Au} / 3 \mathrm{C}-\mathrm{SiC}$ Schottky contacts formed on a region containing double position boundaries (DPB) (open squares) or on a region without DPBs (DPB free) (solid triangles). (b) Schottky barrier height of $\mathrm{Au} / 3 \mathrm{C}-\mathrm{SiC}$ contacts as a function of the contact area, determined in DPB-free regions. The continuous line is fit of the experimental data with the theoretical model discussed in detail in Ref. [151]. 


\section{References}

[1] Ren F and Zolper J C 2003 Wide Band Gap Electronic Devices, Singapore, World Scientific.

[2]Choyke W J, Matsunami H and Pensl G 2004 Silicon Carbide: Recent Major Advances, Berlin, SpringerVerlag.

[3] Shur M, Rumyanstev S and Levinshtein M 2006 SiC Materials and Devices, Singapore, World Scientific, Vol. 1.

[4] Pensl G, Ciobanu F, Frank T, Krieger M, Reshanov S, Schmid F and Weidner M 2006 SiC Materials and Devices, Shur M, Rumyanstev S and Levinshtein M eds., Singapore, World Scientific, Vol. 1, pag. 1-41.

[5] Berkman E, et al. 2009 Mat. Sci. Forum 615-617 3.

[6] Yoon Soon Park 1998, SiC Materials and Devices, Semiconductors and Semimetal, Willardson R K and Weber E R eds., San Diego CA, Academic Press, Vol. 52.

[7] Weitzel C E, Palmour J W, Carter C H, Moore K, Nordquist K J, Allen S and Thero C 1996 IEEE Trans. on Electron Devices 431732.

[8] Roccaforte F, La Via F, Di Franco S and Raineri V 2002 Appl. Phys. Lett. 811125.

[9] Friedriechs P 2008 phys. stat. sol. (b) 2451232.

[10] Zhao J H, Sheng K and Lebron-Velilla RC 2005 Int. J. High Speed Electronics and Systems 15, 821.

[11] McD. Hobgood H et al. 2004 Mat. Sci. Forum 457-460 3.

[12] Roccaforte F, Di Franco S, Giannazzo F, La Via F, Libertino S, Raineri V, Saggio M and Zanetti E 2005 Solid State Phenomena 108-109 663.

[13] Crofton J, Porter L M and Williams J R 1997 phys. stat. sol. (b) 202581.

[14] Roccaforte F, La Via F and Raineri V 2006 SiC Materials and Devices, Shur M, Rumyanstev S and Levinshtein M eds., Singapore, World Scientific, Vol. 1, pag. 77-116.

[15] Giannazzo F, Roccaforte F, Iucolano F, Raineri V, Ruffino F and Grimaldi M G 2009 J. Vac. Sci. Technol. B 27789.

[16] Satoh M and Matsuo H 2006 Mater. Sci. Forum 527-529 923.

[17] Constantinidis G, Kuzmic J, Michelakis K and Tsagaraki K 1998 Solid-State Electronics 42253.

[18] Shenoy P, Moki A, Baliga B J, Alok D, Wongchotigul K and Spencer M 1994 Proc. IEDM 1994. 411.

[19] Waldrop J R and Grant R W 1993 Appl. Phys. Lett. 622685.

[20] Waldrop J R, Grant R W, Wang Y C and Davis R F 1992 J. Appl. Phys. 724757.

[21] Lee S K, Zetterling C M, Östling M, Åberg I, Magnusson M H, Deppert K, Wernersson L E, Samuelson L and Litwin A 2002 Solid State Electronic 46, 1433.

[22] Roccaforte F, La Via F, La Magna A, Di Franco S and Raineri V 2003 IEEE Trans. on Electron Devices 50 1741.

[23] Aboelfotoh M O, Fröjdh C and Petersson C S 2003 Phys. Rev. B 67075312.

[24] Roccaforte F, La Via F, Raineri V, Mangano F and Calcagno L 2003 Appl. Phys. Lett. 834181.

[25] Im H J, Ding Y, Pelz J P and Choyke W J 2001 Phys. Rev. B 64075310.

[26] Bhatnagar M, McLarty P K and Baliga B J 1992 Electron Device Lett. 13501.

[27] Perrone D, Naretto M, Ferrero S, Scaltrito L and Pirri C F 2009 Mater. Sci. Forum 615-617, 647.

[28] Nakamura T, Miyanagi T, Kamata I, Jikimoto T and Tsuchida H 2005 IEEE Electron Device Lett. 2699.

[29] Choi K J, Han S Y and Lee J L 2003 J. Appl. Phys. 941765.

[30] Vassilevski K V, Horsfall A B, Johnson C M, Wright N and G, O'Neill A G 2002 IEEE Trans. Electron Devices 49947.

[31] Lee S K, Zetterling C M and Östling M 2000 J. Appl. Phys. 878039.

[32] Nigam S, et al. 2002 Appl. Phys. Lett. 812385.

[33] Morisette D T, Cooper J A, Melloch M R, Dolny G M, Shenoy P M, Zafrani M and Gladish J 2001 IEEE Trans. Electron Devices 48349.

[34] Roccaforte F, La Via F, Raineri V, Pierobon R and Zanoni E 2003 J. Appl. Phys. 939137.

[35] Itoh A, Kimoto T and Matsunami H 1995 IEEE Electron Device Lett. 16280.

[36] Saxena V, Su J N and Steckl A J 1999 IEEE Trans. Electron Devices 46456.

[37] Schroder D K 2006 Semiconductor Material and Device Characterization, Hoboken - New Jersey, John Wiley and Sons, Third Edition. 
[38] Oder T N, Sutphin E and Kummari R 2009 J. Vac. Sci. Technol. B 271865.

[39] Kwietniewski N, Sochacki M, Szmidt J, Guziewicz M, Kaminska E and Piotrowska A 2008 Appl. Surf. Sci. 2548106.

[40] Schottky W 1938 Naturwissenschaften 26, 843.

[41] Padovani F A and Stratton R 1966 Solid-State Electron. 9695.

[42] Skromme B J, Luckowski E, moore K, Bhatnagar M, Weitzel C E, Gehoski T and Ganser D 2000 J. of Electronic Materials 29376.

[43] Rhoderick E H and Williams R H 1988 Metal-Semiconductor contacts, Oxford Science Publications, Oxford, UK.

[44] Cowley A M and Sze S M 1965 J. Appl. Phys. 363121.

[45] Bardeen J 1947 Phys. Rev. 71717.

[46] Kurtin S, McGill T C and Mead C A 1969 Phys. Rev. Lett. 221433.

[47] Ewing D J, Porter L M, Wahab Q, Ma X, Sudharshan T S, Tumakha S, Gao M and Brillson L J 2007 J.

Appl. Phys 101114514.

[48] Hara S, Teraji T, Okushi H and Kajimura K Appl. Surf. Sci. 117-I 18394.

[49] Raineri V, Giannazzo F and Roccaforte F 2009 Mater. Sci. Forum 615-617 417.

[50] Im H J, Kaczer B, Pelz J P and Choyke W J 1998 Appl. Phys. Lett. 72839.

[51] Bell L D and Kaiser W J 1988 Phys. Rev. Lett. 612368.

[52] Tung R T 1992 Phys. Rev. B 4513509.

[53] Sullivan J, Tung R T, Pinto M and Graham W R 1991 J. Appl. Phys. 707403.

[54] Schmitsdorf R F, Kampen T U and Mönch W 1997 J. Vac. Sci. Technol. B 151221.

[55] Ferhat Hamida A, Ouennoughi Z, Sellai A, Weiss R and Ryssel H 2008 Semicond. Sci. Technol. 23045005.

[56] Gammon P M, Pérez-Tomás A, Shah V A, Roberts G J, Jennings M R, Covington J A and Mawby P A 2009 J. Appl. Phys. 106093708.

[57] Cho H, Leerungnawarat P, Hays D C, Pearton S J, Chu S N G, Strong R M, Zetterling C M, Östling M and Ren F 2000 Appl. Phys. Lett. 76739.

[58] Morrison D J, Pidduck A J, Moore V, Wilding P J, Hilton K P, Uren M J, Johnson C M, Wright N G and O`Neill A G 2000 Semicond. Sci. Technol. 151107.

[59] Khema V, Chow T P and Gutman R J 1998 J. Electr. Mater. 271128.

[60] Morrison D J, Pidduck A J, Moore V, Wilding P J, Hilton K P, Uren M J and Johnson C M 2000 Mat. Sci. Forum 338-3421199.

[61] Roccaforte F, La Via F, Raineri V, Musumeci P, Calcagno L and Condorelli G G 2003 Appl. Phys. A 77 827.

[62] Giannazzo F, Roccaforte F, Raineri V and Liotta S F 2006 Europhysics Lett. 74686.

[63] Sciuto A, Roccaforte F, Di Franco S, Raineri V and Bonanno G 2006 Appl. Phys. Lett. 8908111.

[64] Hiyoshi T and Kimoto T 2009 Appl. Phys. Expr. 2041101.

[65] Storasta L, Bergman J P, Janzén E, Henry A and Lu J 2004 J. Appl. Phys. 964909.

[66] Roccaforte F, Libertino S, Raineri V, Ruggiero A, Massimino V and Calcagno L, J. Appl. Phys. 99013515.

[67] Lee S K et al. 2002 Solid-State Electronics 461433.

[68] Ruffino F, Grimaldi M G, Giannazzo F, Roccaforte F and Raineri V 2006 Appl. Phys. Lett. 89243113.

[69] Roccaforte F, La Via F, Raineri V, Calcagno L and Musumeci P 2001 Appl. Surf. Sci. 184, 295.

[70] Eriksson J, Roccaforte F, Giannazzo F, Lo Nigro R, Raineri V, Lorenzzi J and Ferro G 2009 Appl. Phys. Lett. 94112104.

[71] Han S Y and Lee J L 2002 J. Electrochem. Soc. 149 G189-G193.

[72] Calcagno L, Ruggiero A, Roccaforte F and La Via F 2005 J. Appl. Phys. 98023713.

[73] Pernot J, Contreras S, Camassel J, Robert J L, Zawadzki W, Neyret E and Di Cioccio L 2000 Appl. Phys. Lett. 774359.

[74] Iwata H and Itoh K M 2001 J. Appl. Phys. 896228.

[75] Matsuura H, Komeda M, Kagamihara S, Iwata H, Ishihara R, Hatakeyama T, Watanabe T, Kojima K, Shinohe T and Arai K 2004 J. Appl. Phys. 962708.

[76] Pernot J, Contreras S and Camassel J 2005 J. Appl. Phys. 98023706. 
[77] Roccaforte F, La Via F, Raineri V, Mangano F and Calcagno L 2003 Appl. Phys. Lett. 834181.

[78] La Via F, Galvagno G, Roccaforte F, Ruggiero A and Calcagno L 2005 Appl. Phys. Lett. 87142105.

[79] Kinoshita T, Itoh K M, Schadt M and Pensl G 1999 J. Appl. Phys. 858193.

[80] Iwata H, Itoh K M and Pensl G 2000 J. Appl. Phys. 881956.

[81] Condorelli G, Mauceri M, Pistone G, Perdicaro L M S, Abbondanza G, Portuese F, Valente G L, Crippa D , Giannazzo F, La Via F 2009 Mater. Sci. Forum 600-603 127.

[82] Roccaforte F, Libertino S, Giannazzo F, Bongiorno C, La Via F and Raineri V 2005 J. Appl. Phys. 97 123502.

[83] Zhang Y, Weber W J, Jiang W, Wang C M, Shutthanandan V and Hallen A 2004 J. Appl. Phys. 95, 4012.

[84] Ohshima T, Abe K, Itoh H, Yoshikawa M, Kojima K, Nashiyama I and Okada S 2000 Appl. Phys. A 71

141.

[85] E. M. Handy, M. V. Rao, O. W. Holland, K. A. Jones, M. A. Derenge, N. Papanicolaou, J. Appl. Phys. 88, 5630 (2000).

[86] Negoro Y, Katsumoto K, Kimoto T and Matsunami H 2004 J. Appl. Phys. 96224.

[87] Schmid F, Laube M, Pensl G, Wagner G and Maier M 2002 J. Appl. Phys. 919182.

[88] Troffer T, Peppermuller C, Pensl G, Rottner K and Schoner A 1996 J. Appl. Phys. 803739.

[89] Laube M, Schmid F, Pensl G, Wagner G, Linnarsson M and Maier M 2002 J. Appl. Phys. 92549.

[90] Raineri V, Calcagno L, Giannazzo F, Goghero D, Musumeci P, Roccaforte F and La Via F 2003 Mater. Sci. Forum, 433-436 375.

[91] Canino M, Giannazzo F, Roccaforte F, Poggi A, Solmi S, Raineri V and Nipoti R 2007 Mater. Sci. Forum, 556-557 571.

[92] Bluet J M, Pernot J, Camassel J, Contreras S, Robert J L, Michaud J F and Billon T 2000 J. Appl. Phys. 88 1971.

[93] Negoro Y, Kimoto T, Matsunami H, Schmid F and Pensl G 2004 J. Appl. Phys. 964916.

[94] Mitra S, Rao M V, Papanicolaou N, Jones K A, Derenge M, Holland O W, Vispute R D and Wilson S R 2004 J. Appl. Phys. 9569.

[95] Saks N S, Agarwal A K, Ryu S H and Palmour J W 2001 J. Appl. Phys. 902796.

[96] Saks N S, Suvorov A V and Capell D C 2004 Appl. Phys. Lett. 845195.

[97] Poggi A, Bergamini F, Nipoti R, Solmi S, Canino M and Carnera A 2006 Appl. Phys. Lett. 88162106.

[98] Lazar M, Raynaud C, Planson D, Ch'ante J P, Locatelli M L, Ottavini L and Godignon P 2003 J. Appl. Phys. 942992.

[99] Persson P O A, Hultman L, Janson M S and Hallen A 2006 J. Appl. Phys. 100053521.

[100] Slotte J, Saarinen K, Janson M S, Hallen A, Kuznetsov A Y, Svensson B G, Wong-Leung J and Jagadish C 2005 J. Appl. Phys. 97033513.

[101] Giannazzo F, Roccaforte F and V. Raineri 2007 Appl. Phys. Lett. 91, 202104.

[102] Giannazzo F, Musumeci P, Calcagno L, Makhtari A and Raineri V 2001 Mater. Sci. Semicond. Process. 4 195.

[103] Giannazzo F, Calcagno L, Raineri V, Ciampolini L, Ciappa M and Napolitani E 2001 Appl. Phys. Lett. 79 1211.

[104] Sundaresan S G, Rao M, Tian Y, Ridgway M C, Schreifels J A and Kopanski J J 2007 J. Appl. Phys. 101 073708.

[105] G. Brauer, W. Anwand, W. Skorupa, S. Brandstetter and C. Teichert, J. Appl. Phys. 99, 023523 (2006)

[106] Giannazzo F, Rambach M, Salinas D, Roccaforte F and Raineri V 2009 Mater. Sci. Forum 615-617 457.

[107] Lee K K, Ohshima T, Ohi A, Itoh H and Pensl G 2006 Jap. J. Appl. Phys. 45, 6830.

[108] Handy E M, Rao M V, Jones K A, Derenge M A, Chi P H, Vispute R D, Venkatesan T, Papanicolaou N A and Mittereder J 1999 J. Appl. Phys. 86746.

[109] Vassilevski K V, Wright N G, Nikitina I P, Horsfall A B, O’Neill A G, Uren M J, Hilton K P, Masterton A G, Hydes A J and Johnson C M 2005 Semicond. Sci. Technol. 20271.

[110] Weng M H, Roccaforte F, Giannazzo F, Di Franco S, Bongiorno C, Saggio M and Raineri V 2009 Proc. of International Conference on Silicon Carbide and Related Materials, Nuremberg, 11-16 October, 2009. 
[111] Tournier D, Perez-Tomás A, Godignon P, Millán J, Mank H, Turover D, Hinchley D and Rhodes J 2005 Proc. of the $17^{\text {th }}$ International Symposium on Power Semiconductor Devices \& IC's May 23-26, 2005 Santa Barbara, CA.

[112] Naik H, Tang K and Chow T P 2009 Mat. Sci. Forum 615-617 773.

[113] Schörner R, Friedrichs P and Peters D 1999 IEEE Trans. Electron Dev., 46533.

[114] Das M K 2004 Mat. Sci. Forum 457-460 1275.

[115] Pensl G, Beljakowa S, Frank T, Gao K, Speck F, Seyller T, Ley L, Ciobanu F, Afanas'ev V, Stesmans A, Kimoto T and Schöner A 2008 phys. stat. sol. (b) 2451378.

[116] Koh A, Kestle A, Wright C, Wilks S P, Mawby P A and Bowen W R 2001 Appl. Surf. Sci. 174210.

[117] Bassler M, Pensl G and Afanas'ev V 1997 Diamond and Related Materials 61472.

[118] Afanas' ev VV 1999 Microelctronics Engineering 48241.

[119] Vathulya V R, Wang D N and White M H 1998 Appl. Phys Lett. 732161.

[120] Afanas'ev V V, Stesmans A, Bassler M, Pensl G, Schulz M J and Harris C I 1996 Appl. Phys. Lett. 68 2141.

[121] Chang K C, Nuhfer N T, Porter L M and Wahab Q 2000 Appl. Phys. Lett. 772186.

[122] Ciobanu F, Pensl G, Afanas'ev V and Schöner A 2005 Mater. Sci. Forum 483-485 693.

[123] Moscatelli F, Poggi A, Solmi S and Nipoti R 2008 IEEE Trans. Electron Devices 55691.

[124] Poggi A, Moscatelli F, Solmi S, Artigliato A, Belsito L and Nipoti R 2010 J. Appl. Phys. 107044506.

[125] Allerstam F, Gudjönsson G, Ólafsson H Ö, Sveinbjörnsson E Ö, Rödle T and Jos R 2007 Semiconductor Sci. Technol. 22307.

[126] Li H, Dimitrijev S, Harrison H B and Sweatman D 1997 Appl. Phys. Lett. 702028.

[127] Jamet P and Dimitrijev S 2001 Appl. Phys. Lett. 79323.

[128] McDonald K, Weller R A, Pantelides S T, Feldman L C, Chung G Y, Tin C C and Williams J R 2003 J. Appl. Phys. 932719.

[129] Wang Y, Tang K, Balasubramanian M K, Naik H, Wang W and Chow T P 2008 IEEE Trans. Electron Devices $\mathbf{5 5} 2046$.

[130] Zheleva T, Lelis A, Duscher G, Liu F, Levin I and Das M 2008 Appl. Phys. Lett. 93022108.

[131] Biggerstaff T L, Reynolds C L, Zheleva T, Lelis A, Habersat D, Haney S, Ryu S-H, Agarwal A and Duscher G 2009 Appl. Phys. Lett. 95032108.

[132] Stedile F C, Corrêa S A, Radtke C, Soares G V and Miotti L 2009 Proc.of International Conference on Silicon Carbide and Related Materials, Nuremberg, 11-16 October, 2009.

[133] Fiorenza P and Raineri V 2006 Appl. Phys. Lett. 88212112.

[134] Fiorenza P, Lo Nigro R, Raineri V and Salinas D 2007 Mater. Sci. Forum 556-557 501.

[135] C, Brandão R V, Pezzi R P, Morais J, Baumvol I J R, Stedile FC 2002 Nucl. Instr. Meth. B 190579.

[136] Jayatirtha H N and Spencer M G 1996 Mat. Res. Soc. Symp. Proc. 410329.

[137] Lebedev A A 2006 Semicond. Sci. Technol. 21 R17-R34.

[138] Schöner A, Krieger M, Pensl G, Abe M and Nagasawa H 2006 Chem. Vap. Deposition 12523.

[139] Severino A, D’Arrigo G, Buongiorno C, Scalese S, La Via F and Foti G 2007 J. Appl. Phys. 102023518.

[140] Nagasawa H, Abe M, Yagi K, Kawahara T and Hatta N 2008 phys. stat. sol. (b) 2451272.

[141] Ohsima T et al. 2003 Jap. J. Appl. Phys. 42 L625.

[142] Schöner A, Bakowski M, Ericsson P, Strömberg H, Nagasawa H and Abe M 2006 Mater. Sci. Forum 5275291273.

[143] Soueidan M and Ferro G 2006 Adv. Funct. Mater. 16975.

[144] Fissel A 2001 J. Crystal Growth 227-228 805.

[145] Bechstedt F, Käckell P, Zywietz A, Karch K, Adolph B, Tenelsen K and Furthmüller J 1997 phys. stat. sol.

(b) 202,35 .

[146] Bechstedt F, Fissel A, Furthmüller J, Kaiser U, Weissker H-Ch and Wesch W 2003 Appl. Surf. Sci. 212213820.

[147] Polyakov V M and Schwierz F 2005 J. Appl. Phys. 98023709.

[148] Chandrashekhar M V S, Thomas C I, Lu J and Spencer M G 2007 Appl. Phys. Lett. 90173509.

[149] Chandrashekhar M V S, Thomas C I, Lu J and Spencer M G 2007 Appl. Phys. Lett. 91033503. 
[150] Lu J, Thomas C I, Chandrashekhar M V S and Spencer M G 2009 J. Appl. Phys. 105106108.

[151] Eriksson J, Weng M H, Roccaforte F, Giannazzo F, Leone S and Raineri V 2009 Appl. Phys. Lett. 95 081907.

[152] Giannazzo F, Goghero D, Raineri V 2004 J. Vac. Sci. Technol. B 222391.

[153] Giannazzo F, Raineri V, Mirabella S, Impellizzeri G, and Priolo F 2006 Appl. Phys. Lett. 88043117.

[154] Eyben P, Xu M, Duhayon N, Clarysse T, Callewaert S, Vandervorst W 2002 J. Vac. Sci. Technol. B 20 471.

[155] Lu RP, Kavanagh KL, Dixon-Warren StJ, Kuhl A, SpringThorpe AJ, Griswold E, Hillier G, Calder I, Ares R, Streater R, 2001 J. Vac. Sci. Technol. B 191662. 


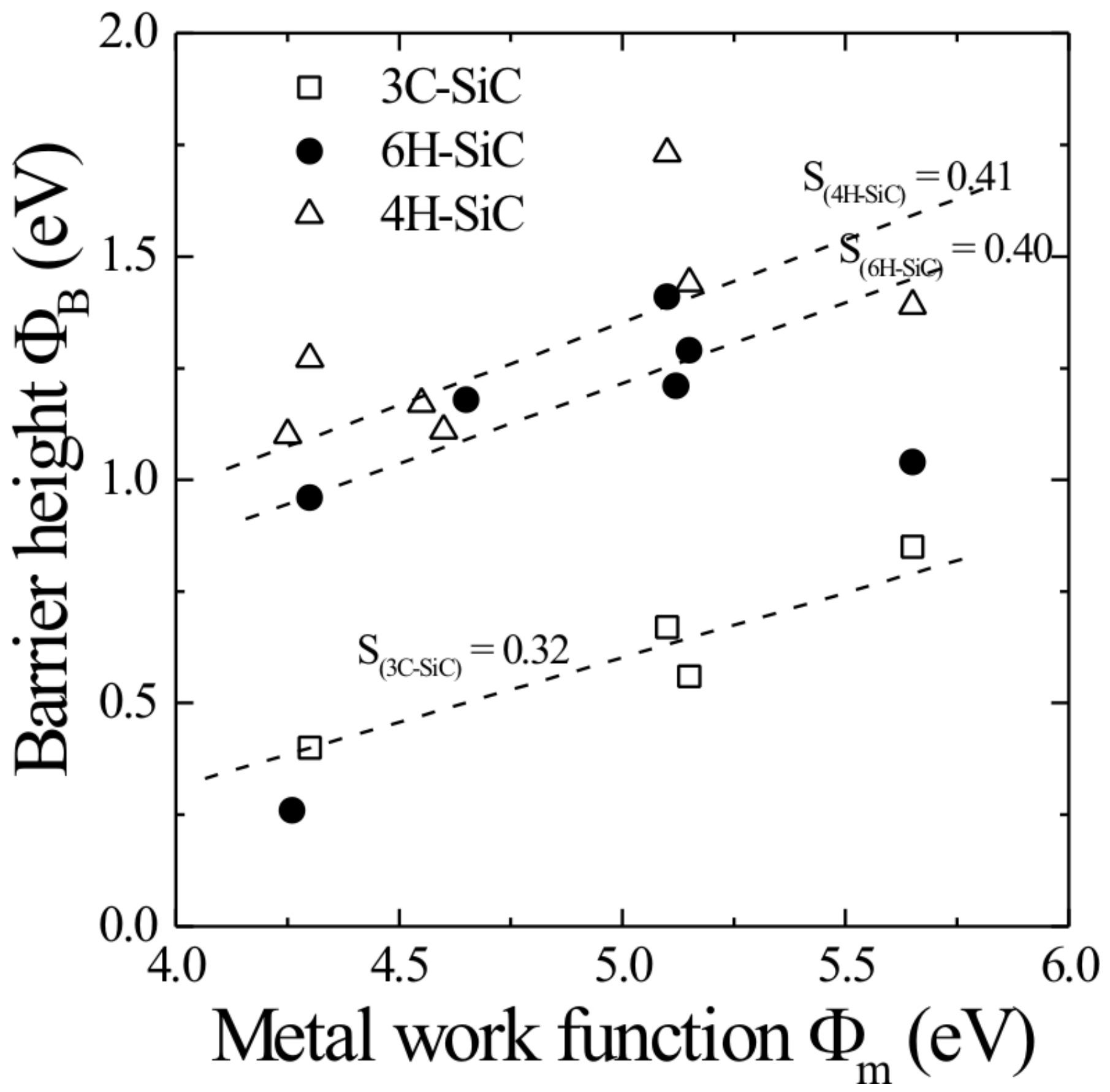

Figure 1 (figure1.tif) 


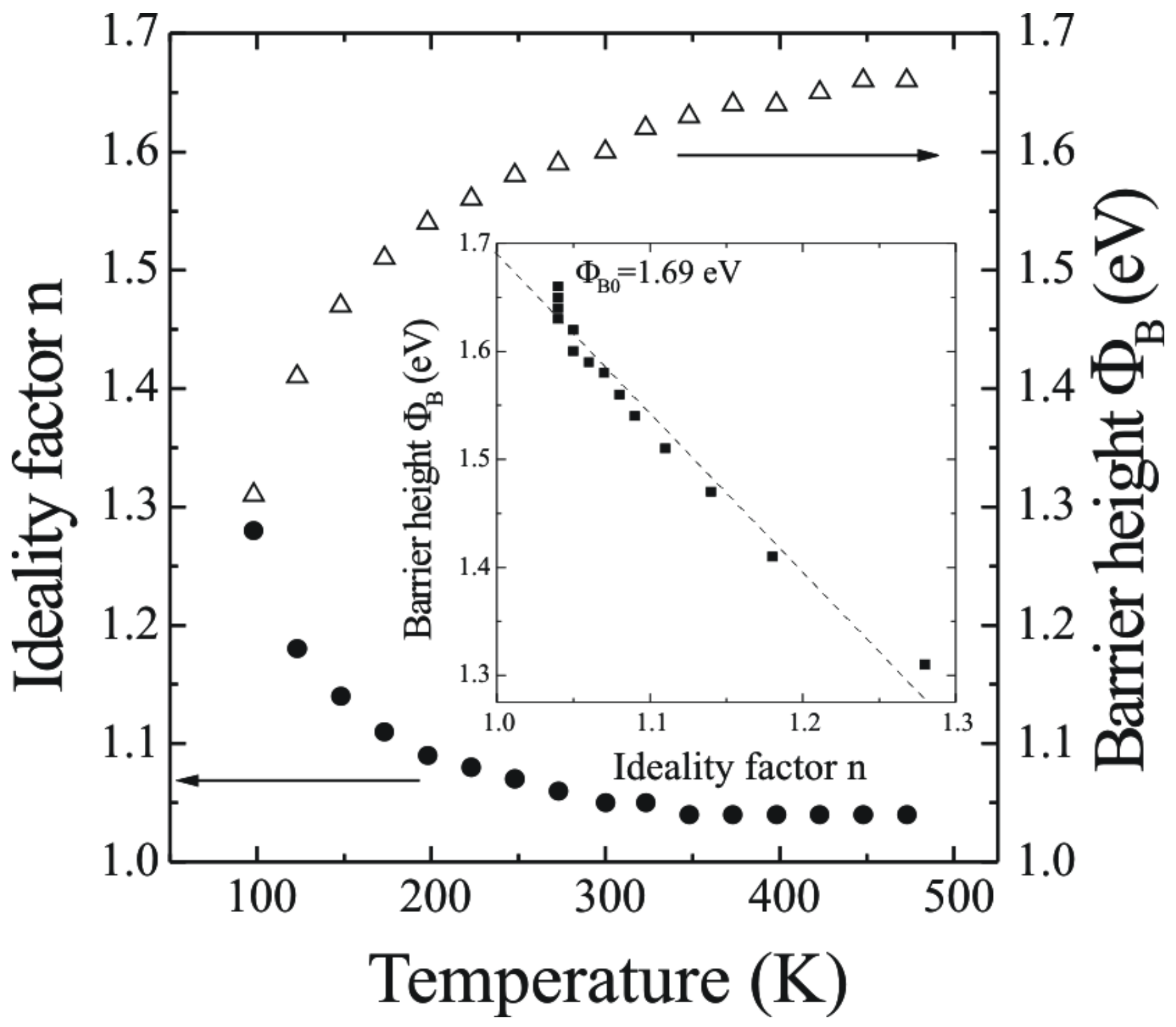

Figure 2 (figure2.tif) 


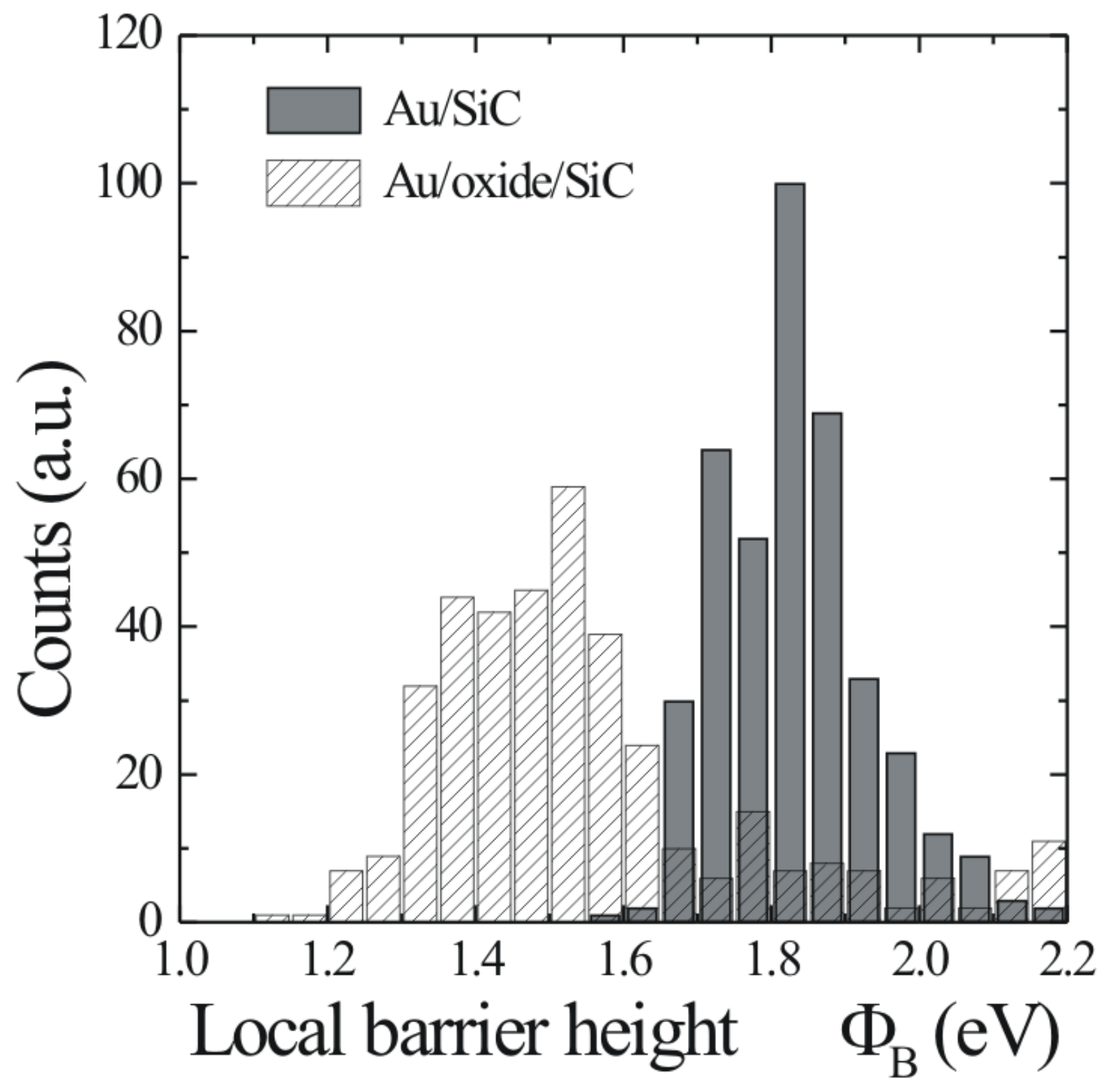

Figure 3 (figure3.tif) 

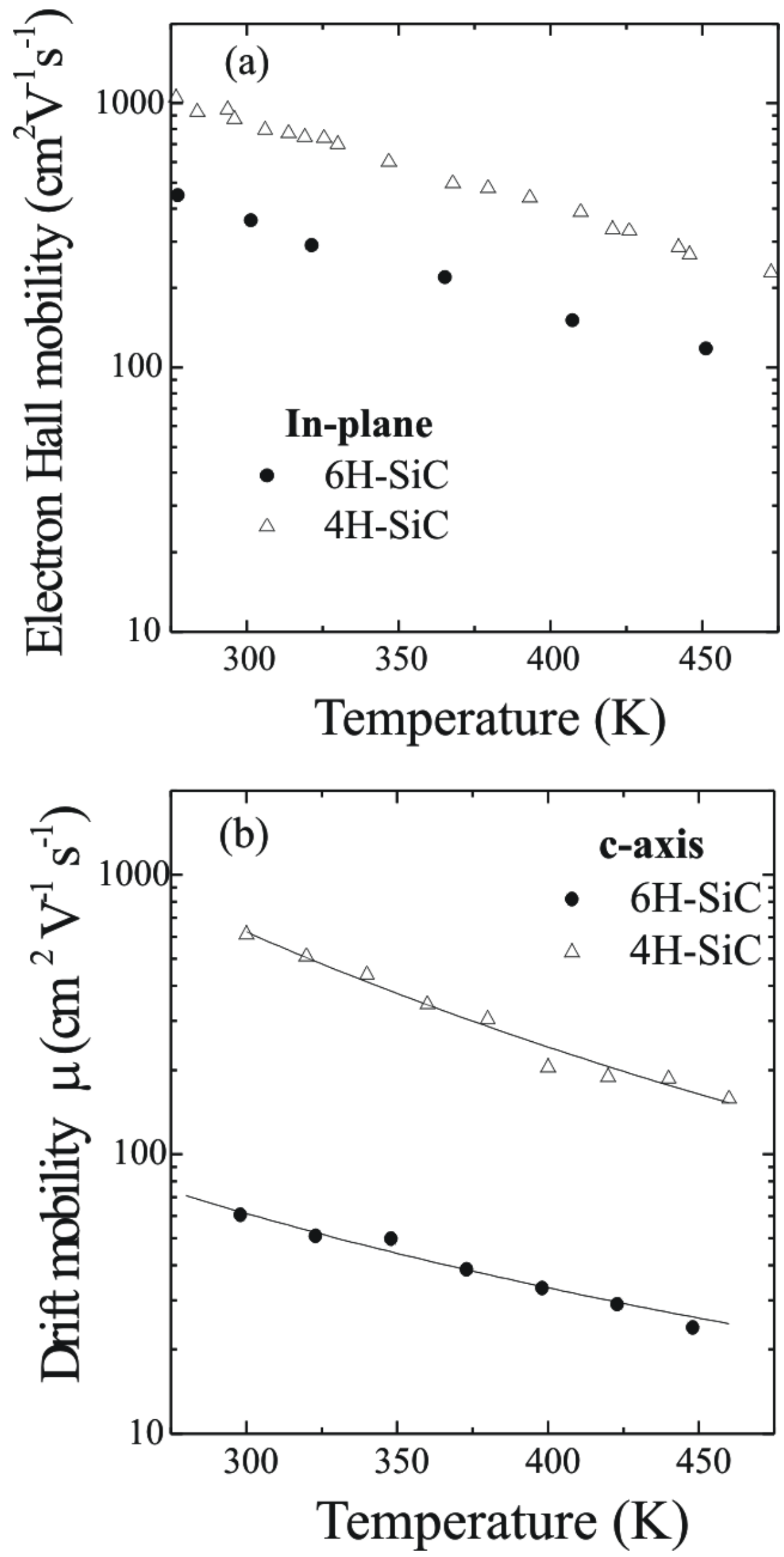

Figure 4 (figure4.tif) 


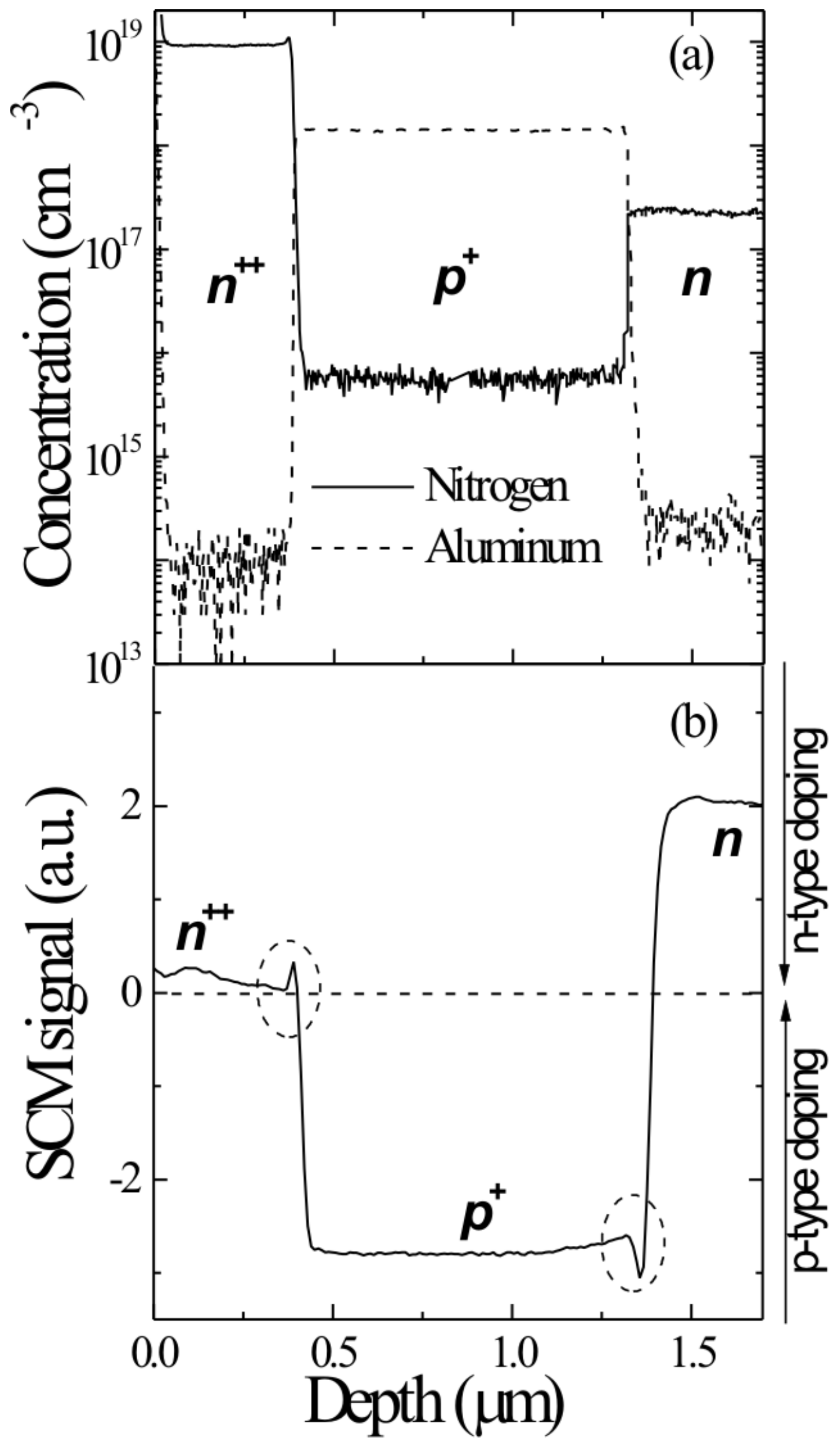

Figure 5 (figure5.tif) 


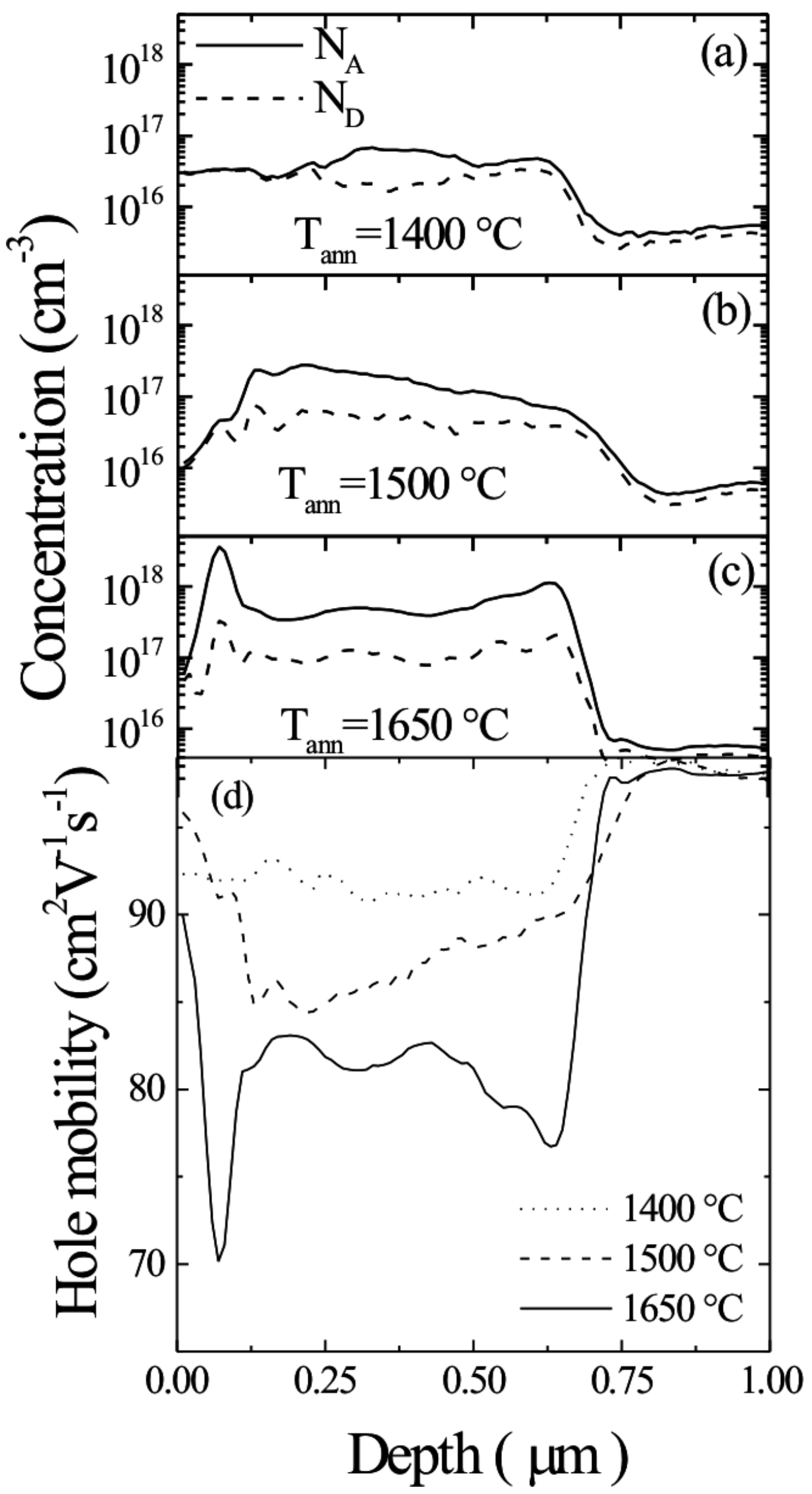

Figure 6 (figure6.tif) 


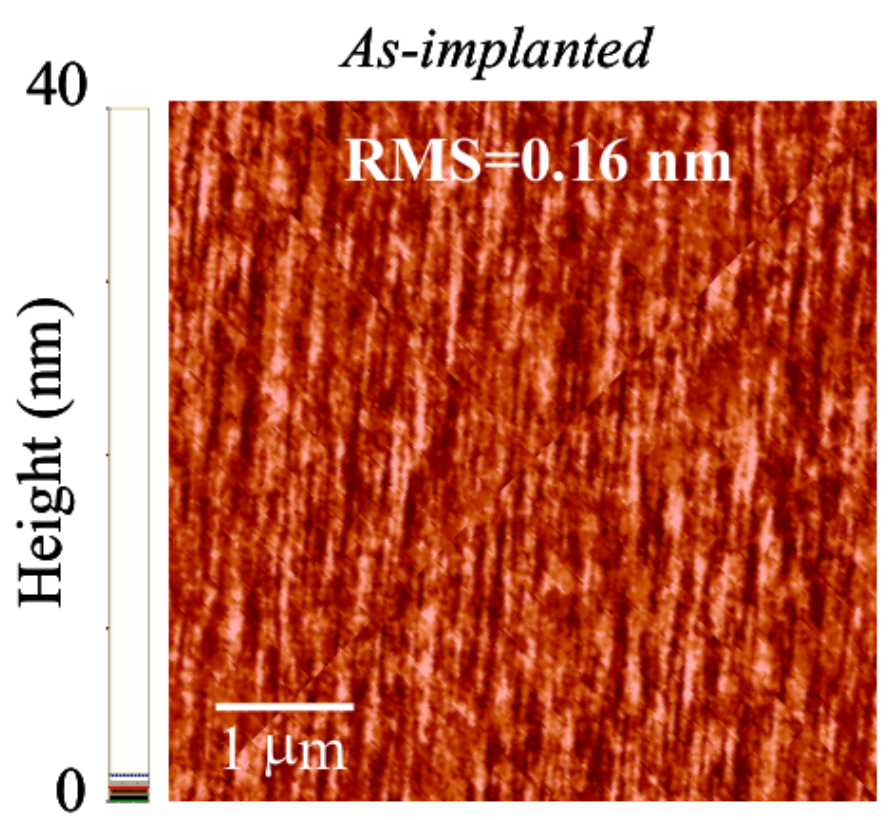

(a)

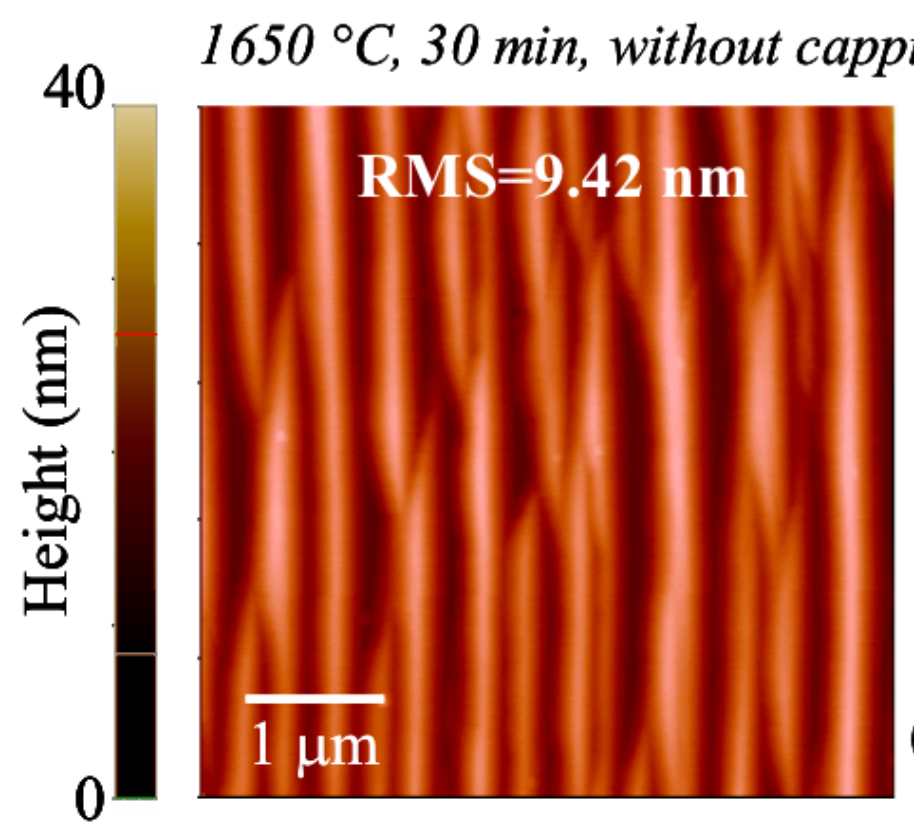

(b)

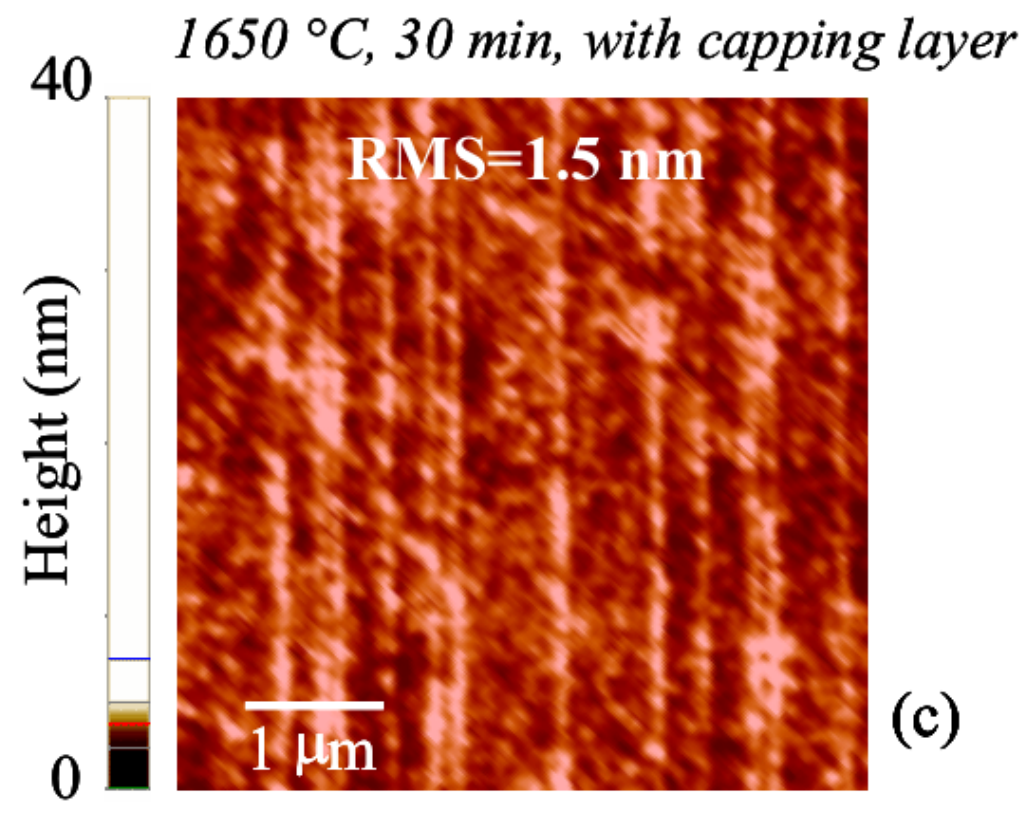

Figure 7 (figure7.tif) 


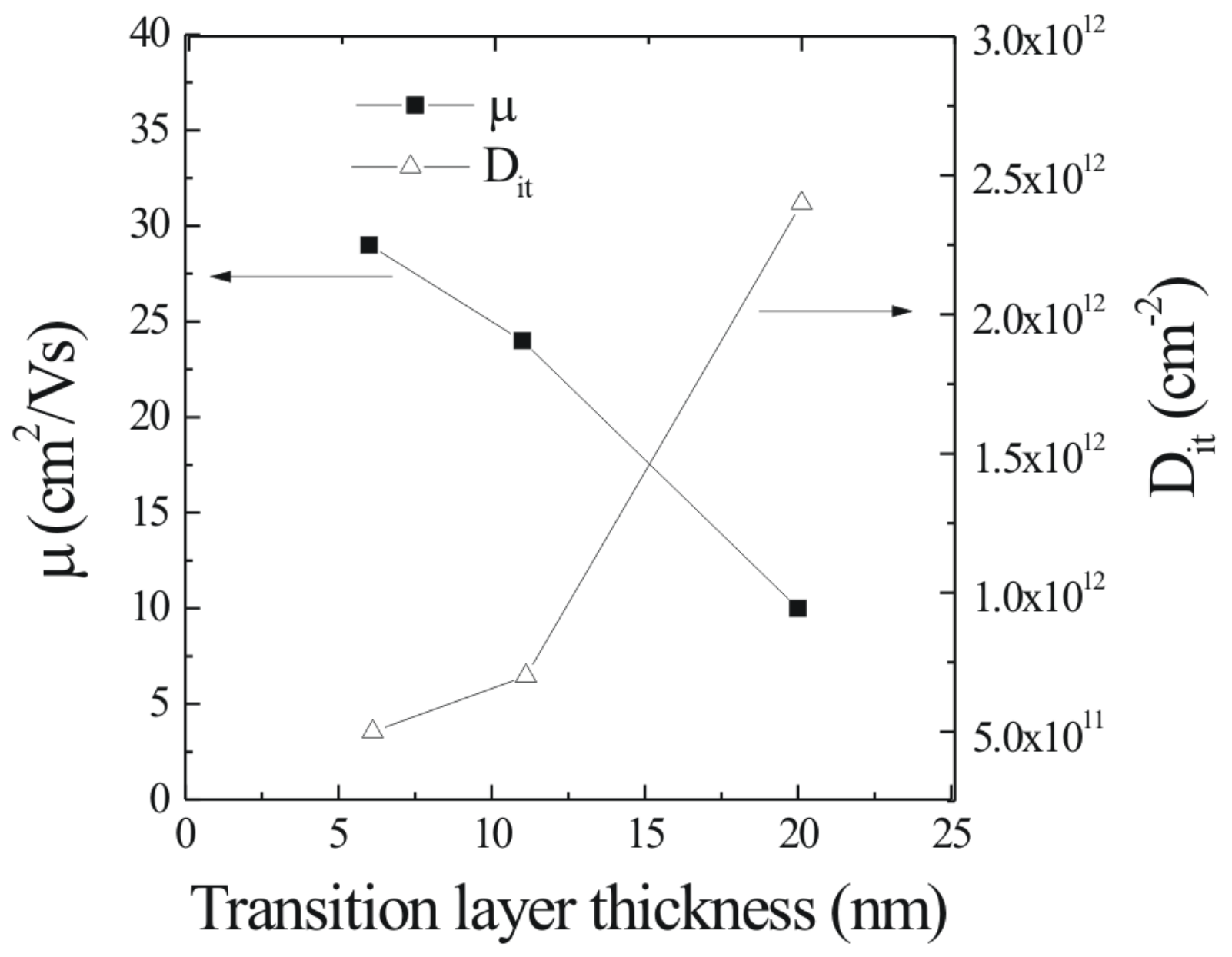

Figure 8 (figure8.tif) 


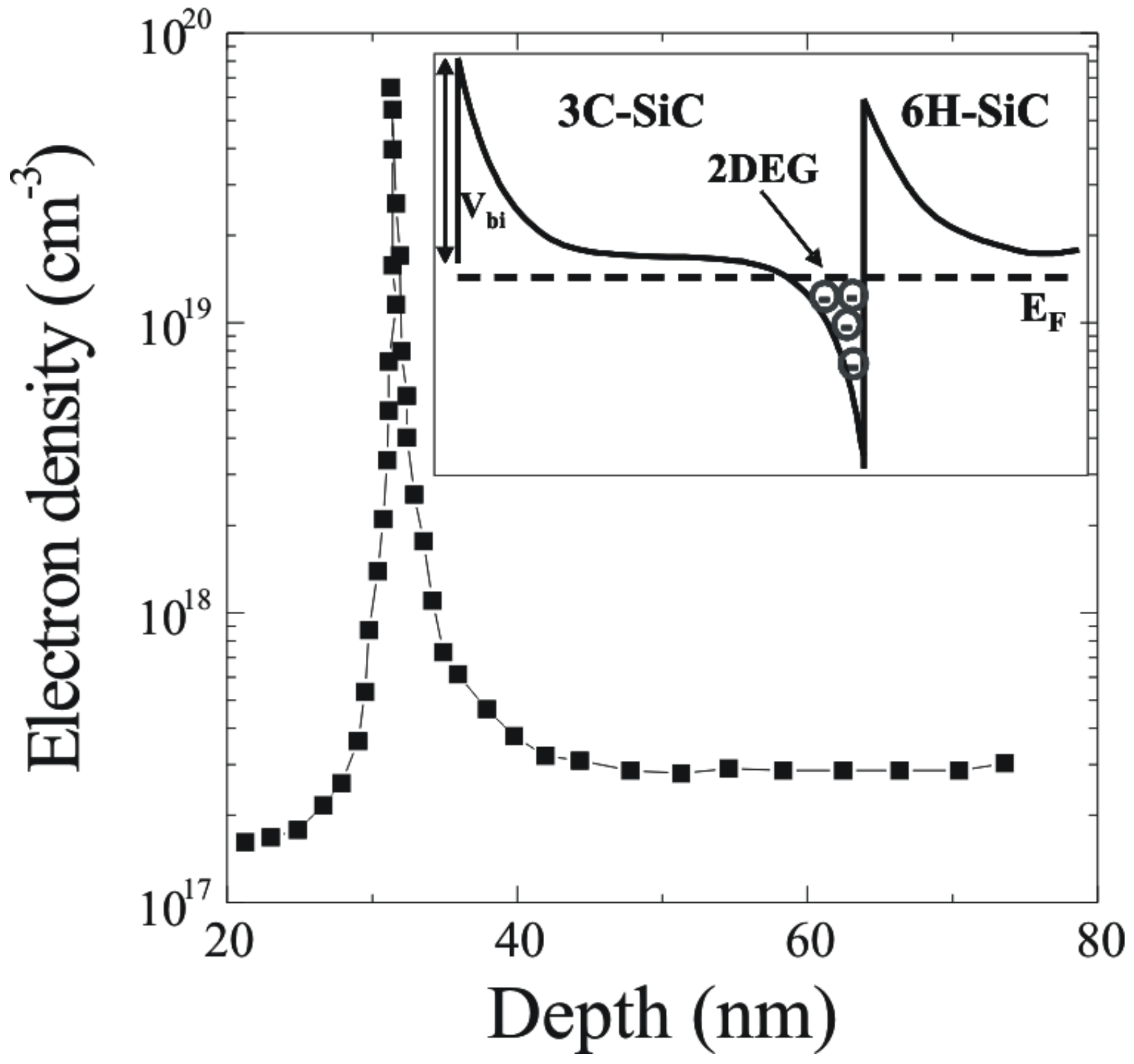

Figure 9 (figure9.tif) 

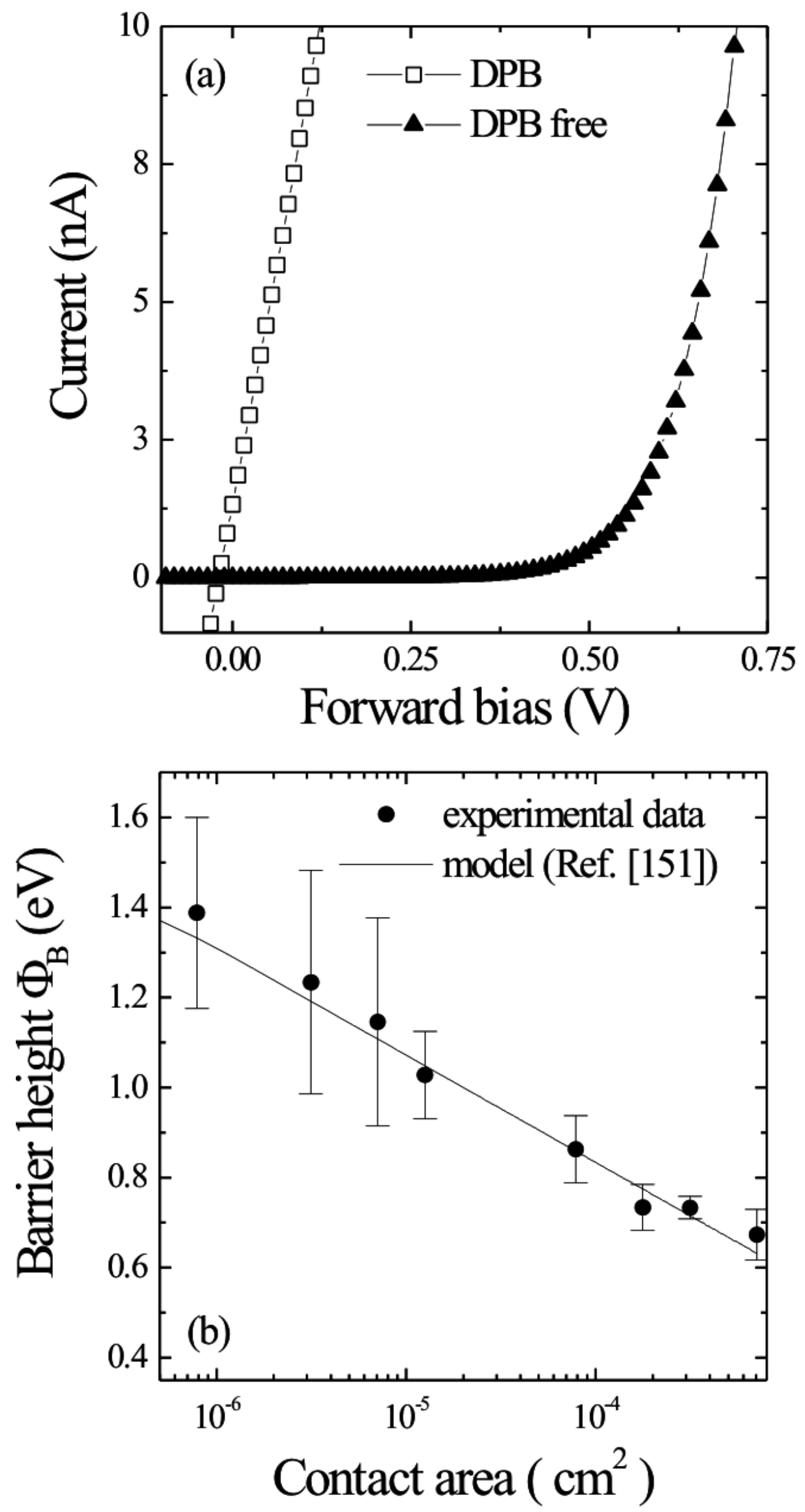

Figure 10 (figure10.tif) 